\title{
On the evaluation of the phase relation between temperature and wind tides based on ground-based measurements and reanalysis data in the middle atmosphere
}

\author{
Kathrin Baumgarten ${ }^{1}$ and Gunter Stober ${ }^{1,2}$ \\ ${ }^{1}$ Leibniz-Institute of Atmospheric Physics at the University of Rostock, Kühlungsborn, Germany \\ ${ }^{2}$ Institute of Applied Physics, Microwave Physics, University of Bern, Bern, Switzerland
}

Correspondence: Kathrin Baumgarten (k.baumgarten@iap-kborn.de)

Received: 20 February 2019 - Discussion started: 8 March 2019

Revised: 12 June 2019 - Accepted: 19 June 2019 - Published: 18 July 2019

\begin{abstract}
The variability in the middle atmosphere is driven by a variety of waves covering different spatial and temporal scales. We diagnose the variability in the thermal tides due to changes in the background wind by an adaptive spectral filter, which takes the intermittency of tides into account. We apply this diagnostic to temperature observations from daylight-capable lidar at midlatitudes $\left(54^{\circ} \mathrm{N}, 12^{\circ} \mathrm{E}\right)$ as well as to reanalysis data of horizontal winds from Modern-Era Retrospective analysis for Research and Applications, Version 2 (MERRA-2). These reanalysis data provide additional wind information in the altitude range between 30 and $70 \mathrm{~km}$ at the location of the lidar as well as on a global scale. Using the global data gives information on the tidal modes seen at one location. A comparison of the temperature and wind information affirms whether there is a fixed phase relation of the tidal waves in the temperature and the wind data. We found that in general the local tidal signatures are dominated by migrating tidal modes, and the signature is weaker in temperatures than in winds. While the meridional wind tide leads the zonal wind tide by $90^{\circ}$, the phase relation between the temperature and the wind tide is more complex. At certain altitudes the temperature tide follows the zonal wind tide. This knowledge helps in improving the interpretation of the seasonal variation in tides from different observables, especially when only data from single locations are used. The findings provide additional information about the phase stability of tidal waves, and the results clearly show the importance of a measurement acquisition on a routine basis with high temporal and spatial resolution.
\end{abstract}

\section{Introduction}

Atmospheric waves play a major role in the circulation of the Earth's atmosphere, as they couple the different atmospheric layers. These waves are often generated in the troposphere and propagate to higher altitudes, where they become dynamically unstable and break and deposit their momentum and energy to the mean flow (e.g., Fritts and Alexander, 2003). Especially such waves driven by the absorption of solar radiation are one of the strongest perturbations in the middle atmosphere. These so-called thermal tides are globalscale waves with periods of 1 solar day and the subharmonics of that day (24, 12 and $8 \mathrm{~h}$; e.g., Chapman and Lindzen, 1970; Forbes, 1984; Hagan and Forbes, 2002). If tides propagate synchronously to the Sun (westward) around the globe they are usually called migrating, while tides are called nonmigrating when the horizontal propagation is in the opposite direction (eastward) or stationary. Tides which also propagate westward but with a zonal wave number other than 1 for the diurnal component, other than 2 for the semidiurnal component and so on are also called non-migrating. Such tides are assumed to be excited mainly by zonally asymmetric variations in topography or time-varying heat sources (Lieberman et al., 2015; Sakazaki et al., 2015).

Global tidal fields have recently been extracted from satellite instruments. For example, tidal climatologies in the mesosphere and lower thermosphere (MLT) region have been constructed by temperature or wind observations from the High Resolution Doppler Interferometer (HRDI), the Wind Imaging Interferometer (WINDII) and the Microwave Limb Sounder (MLS) on board the Upper Atmosphere Research 
Satellite (UARS) or from the TIMED Doppler Interferometer (TIDI) and from the Sounding of the Atmosphere using Broadband Emission Radiometry (SABER) instrument on board the TIMED (Thermosphere Ionosphere Mesosphere Energetics and Dynamics) satellite (e.g., McLandress et al., 1996; Forbes and Wu, 2006; Sakazaki et al., 2012; Pancheva et al., 2013). Most satellite studies have focused on the MLT region due to the large effect of tides at these altitudes. Only a few satellite studies deal with the lower atmospheric region (Zhang et al., 2006; Mukhtarov et al., 2009; Sakazaki et al., 2018). However, satellites typically need several weeks to cover $24 \mathrm{~h}$ of local time at one particular location. Therefore, tidal results from satellite measurements are typically based on monthly mean values. Consequently, the short-term variability in timescales of less than a month cannot be resolved from those instruments. Nowadays, there are a few approaches for extracting the short-term variability in tides from satellite data using a deconvolution method for nonmigrating tidal modes or with the combination of groundbased radar and satellite observations (Oberheide et al., 2002; Lieberman et al., 2015; Pedatella et al., 2016; Zhou et al., 2018). But these approaches are limited to lower latitudes $\left(<50^{\circ} \mathrm{N}\right)$, resolving only non-migrating tides, or they are limited to the MLT region (Oberheide et al., 2002; Zhou et al., 2018). Therefore, these methods are not suitable for resolving the day-to-day variability in tides at latitudes of $54^{\circ} \mathrm{N}$ over the whole altitude range of the middle atmosphere.

In contrast to satellite data, ground-based observations have the advantage of a high temporal and spatial resolution in deriving tidal information at a certain location. Tidal observations require full-day data coverage, which is achieved using daylight-capable lidars or radars (Fong et al., 2014; Kopp et al., 2015; Jacobi, 2012; Pokhotelov et al., 2018). Radars typically provide quasi-continuous data sets of horizontal winds, but unfortunately these instruments cover only a limited altitude range between approximately 70 and $110 \mathrm{~km}$ in the MLT region (Hoffmann et al., 2010; Wilhelm et al., 2017). Lidar using Rayleigh scattering is also able to provide temperature data in the altitude range below the mesopause whenever the weather is appropriate, and thus, also the stratosphere and mesosphere is covered. Based on multi-day time series of temperature data, lidar provides useful case studies for investigating the short-term variability in tides. But using data solely from temperatures will resolve only one part of the wave activity because the wind information is missing. A combination of temperature and wind information would yield a deeper understanding of the dynamics, including wave dissipation and wave filtering mechanisms as well as the phase relation between the different observables. Therefore, this study combines ground-based lidar with reanalysis data. Reanalysis data provide additional data where observations are missing by assimilating existing observations combined with an underlying forecast model resulting in global gridded data sets for a broad range of vari- ables. For instance the Modern-Era Retrospective analysis for Research and Applications, Version 2 (MERRA-2), produces temperature and wind fields over several years from the surface up to the lower mesosphere (Gelaro et al., 2017). Sakazaki et al. $(2012,2018)$ investigated the representation of tides in several reanalysis data sets as well as in satellite data. In general, the results of the studies show a consistent diurnal migrating, semidiurnal migrating and non-migrating tidal representation in all data sets used from a global perspective. But there are differences in amplitude and phase for the diurnal migrating tide between reanalyses and SABER due to a different representation of a trapped tidal mode. The reason for that is either an underestimated stratospheric ozone in the forecast model of the reanalyses or some local time biases in the temperature retrieval of SABER.

The dynamic fields of temperature and wind fluctuations induced by tides are similarly related to the polarization relation of gravity waves. Such a polarization relation for tides was theoretically derived from the primitive equations for fluctuations of an atmosphere without dissipation by She et al. (2016). They showed that there is a fixed relation between both wind components and the temperature fluctuations induced by tides from the investigation of $\mathrm{Na}$ lidar measurements and model predictions from the Climatological Tidal Model of the Thermosphere (CTMT) based on the Hough mode extension (HME) technique in the MLT region. A derivation and affirmation of a tidal polarization relation would lead to a possibility of deducing an unknown tidal field from another observed tidal field and are therefore also highly recommended for the altitude range below the mesopause region. For a westward-propagating monochromatic wave with a single zonal wave number $s$, the polarization relation between the temperature tide $\widetilde{T}$ and the zonal wind tide $\widetilde{u}$ derived by She et al. (2016) is

$\widetilde{T}=\frac{H}{R}\left(i \widetilde{m}(z)+\frac{1}{2 H}\right) \frac{\sigma^{2}-f^{2}}{\sigma k} \widetilde{u}$,

with the horizontal wave vector $k=\frac{2 \pi s}{2 \pi a \cos \phi}$, the vertical wave number $m$, Earth's radius $a$, the latitude $\phi$, the Coriolis frequency $f$, the angular frequency of the tidal wave $\sigma$ and the scale height $H$ at a reference altitude. This relation is not valid for a so-called trapped tidal mode as well as nonmigrating tides. Consequently, it has to be proven if the relation still holds for tidal observations in the stratosphere and lower mesosphere, where those tides can occur (e.g., Forbes and Garrett, 1979).

Therefore, this paper presents tidal signatures derived from temperature and wind data using a Rayleigh-MieRaman (RMR) lidar and reanalysis data from MERRA-2 covering an altitude range between 30 and $70 \mathrm{~km}$ during a multi-day time series of observations in May 2016 at $54^{\circ} \mathrm{N}$, $12^{\circ} \mathrm{E}$. To our knowledge, this $230 \mathrm{~h}$ long data set is still the longest continuous data set retrieved by an RMR lidar. The daylight capability of this RMR lidar as well as exceptionally 
good weather conditions made it possible to investigate wave structures over this time period, which allowed the study of not only the short-term variability in gravity waves and tides but also the tidal phase progression. The short-term variability in the atmospheric waves during this case study in May 2016 has already been described in Baumgarten et al. (2018), showing a large variability also for tidal signatures, which coincides with an increase in gravity waves at exactly the time and place where the diurnal tidal component showed a strong decrease. However, the current paper focuses on the tidal phase relations observed in different quantities. A unified approach is presented in this study to retrieve tidal fields of different data sets from different instruments. This approach is able to deal with data gaps and unequally sampled data, which is often the case for observational data, and it enables a decomposition of the data into a tidal field, a background due to planetary waves, and variations due to gravity waves with resolving amplitudes and phases during the sounding period.

The organization of the paper is as follows. In Sect. 2 we describe the different data sets for temperature and wind information using measurements as well as reanalysis data and how the data are treated using a unified diagnosing tool for tides. Section 3 presents the results for the tidal analysis as comparison of the tidal fluctuations simultaneously seen in temperature and wind data during the case study in May 2016. The results of the phase relation are discussed in Sect. 4. Finally, the findings are summarized and a conclusion is given in Sect. 5.

\section{Description of the data and analysis methods}

\subsection{Data}

The temperature data used in this study were obtained by the RMR lidar at Kühlungsborn $\left(54^{\circ} \mathrm{N}, 12^{\circ} \mathrm{E}\right)$. This lidar was developed in 2009/2010 to measure the backscattered signal independently of any daylight conditions. Therefore, a commercial frequency-doubled Nd:YAG laser at $532 \mathrm{~nm}$ is used as an emitter. The laser beam is guided co-axially with the receiving telescope into the atmosphere. The field of view (FOV) of the receiver is limited by a fiber cable with a small core diameter of $0.2 \mathrm{~mm}$, resulting in a small field of view of only $62 \mu \mathrm{rad}$. The advantage is a reduction of the scattered background light from the Sun. A narrow band interference filter (IF) as well as a double Fabry-Pérot etalon (FPE) is used for spectral filtering. The IF has a full width at half maximum (FWHM) of about $130 \mathrm{pm}$, the double etalon of about $4 \mathrm{pm}$. A detailed description of the lidar was given in Gerding et al. (2016).

From the range-corrected backscattered signal, absolute temperatures are derived assuming hydrostatic equilibrium (Hauchecorne and Chanin, 1980). The initial temperature value for integration is taken from CIRA-86 (Fleming et al.,
1990) in an altitude range between 70 and $75 \mathrm{~km}$ for the whole day due to the strong solar background at the highest solar elevation. The temperatures become independent of the start temperature approximately 1-2 scale heights below the initial retrieval altitude. The integration time to retrieve the temperatures is $2 \mathrm{~h}$, with a temporal shift of $15 \mathrm{~min}$. The vertical resolution is $1 \mathrm{~km}$. Due to additional aerosol scattering below $30 \mathrm{~km}$ only lidar temperatures above this altitude are taken into account in this paper.

NASA's Global Modeling and Assimilation Office (GMAO) produced the MERRA-2, which assimilates a variety of observations from radiosondes, satellites, ships and land observations (Gelaro et al., 2017). The improvements of MERRA-2 compared to the former version are the assimilation of aerosol observations and better representations of the stratospheric ozone and cryospheric processes. In addition to this, some jumps, trends and biases in aspects of the water cycle in MERRA-2 are reduced to improve the quality of the reanalysis data. The underlying general circulation model is the Goddard Earth Observing System (GEOS) Version 5, which was improved in the dynamical core and the physical parameterization scheme. With the assimilated observational data the model provides, including the first version of MERRA, time series of data products from 1979 to present with a horizontal resolution of $0.5^{\circ} \times 0.625^{\circ}$. The data products have 72 model and pressure levels from the surface to $0.01 \mathrm{hPa}(0.1-75 \mathrm{~km})$, with a variable vertical resolution between $100 \mathrm{~m}$ in the troposphere and up to $4 \mathrm{~km}$ in the lower mesosphere. The time series of temperature and wind data from MERRA-2 used for this study has a temporal resolution of $3 \mathrm{~h}$.

\subsection{Methods for the tidal analysis}

Time series of temperatures and winds observed by groundbased instruments reveal dynamical processes in the atmosphere over a certain altitude range. Those data sets contain an observation of a superposition of a slowly varying background which is disturbed by small-scale waves like gravity waves. To decompose such temperature and wind data sets, some a priori knowledge is necessary for retrieving tidal signatures. By assuming fixed periods as well as assuming large vertical wavelengths for thermal tides, we have developed an adaptive spectral filtering (ASF) technique to decompose the time series into a background (for temperature $T_{0}$, zonal wind $u_{0}$ and meridional wind $v_{0}$ ) and the tidal components ( $T_{\text {fil }}, u_{\text {fil }}$ and $v_{\text {fil }}$ ) according to the following equation:

$$
\begin{aligned}
& T_{\text {fil }}, u_{\text {fil }}, v_{\text {fil }}=T_{0}, u_{0}, v_{0}+\sum_{n=1}^{3}\left(A_{n} \cdot \sin \left(\frac{2 \pi}{P_{n}} \cdot t\right)\right. \\
& \left.+B_{n} \cdot \cos \left(\frac{2 \pi}{P_{n}} \cdot t\right)\right),
\end{aligned}
$$

where $P_{n}$ is 24,12 and $8 \mathrm{~h}$ and $A_{n}$ and $B_{n}$ denote the coefficients for the tidal amplitudes based on temperatures, zonal 
or meridional winds. A detailed explanation is given in Stober et al. (2017), but that study is done without taking the information about the vertical wavelengths into account. In a first step, we fit all coefficients to derive mean temperatures and winds (zonal and meridional component) as well as tidal amplitudes and phases for the diurnal, semidiurnal and terdiurnal component. The initial window length is $2 \mathrm{~d}$. In further steps, the window size is adapted to the number of wave cycles to better account for the intermittency of waves. Therefore, the second step uses a window length of $24 \mathrm{~h}$, and the semidiurnal tide and terdiurnal tidal amplitude and phase are fitted using the mean and diurnal tidal amplitude and phase as a regularization constraint. The terdiurnal tidal amplitude and phase are obtained with a window length of $16 \mathrm{~h}$ and by inserting the mean, the diurnal, and the semidiurnal amplitude and phase as a regularization constraint. This procedure is repeated for every data point of the time series. Thus, there is a resulting time series of mean temperatures and winds, diurnal, semidiurnal and terdiurnal amplitudes and phases with the same resolution as the observations. The remaining variation is assumed to be due to gravity waves.

It turns out that the adaptive spectral filter, if applied just in the time domain without further knowledge of vertical wavelengths, does indeed provide a proper decomposition of the mean winds and the tidal components. But it appears that gravity waves with similar periods to tides (especially with a period of $\approx 12 \mathrm{~h}$ ) but with smaller vertical wavelengths are also interpreted as tides. To avoid this, we introduced a vertical regularization in the fitting procedure, assuming that the mean temperature and wind only show a small change with altitude under the assumption that the vertical wavelength of tides is larger than that of gravity waves with periods around $12 \mathrm{~h}$. We use a $8 \mathrm{~km}$ vertical regularization for the mean state and a $16 \mathrm{~km}$ vertical regularization for the tidal phases. These thresholds are based on the wavelet analysis presented in Baumgarten et al. (2017). This study showed that such inertia gravity waves typically have vertical wavelengths of about $8 \mathrm{~km}$, while gravity waves with much smaller periods have comparably large vertical wavelengths in the range of those from tides. Studies such as those by Mukhtarov et al. (2009) and Kopp et al. (2015) as well as model results from Forbes (1984) revealed vertical wavelengths of the diurnal tide between 15 and $50 \mathrm{~km}$ or even larger wavelengths for the semidiurnal tide. The vertical wavelength is in general largest for the first Hough modes and decreases with higher modes (Forbes, 1995). But observations suggest that only the first Hough modes are relevant in the atmosphere. Therefore, it is a suitable assumption to use $16 \mathrm{~km}$ as a vertical regularization constraint. The regularization is implemented by allowing only a gradual change of the mean amplitudes or tidal phases for each vertical cut-off wavelength. This approach is more suitable to also separate gravity waves with shorter vertical wavelengths from tides. The advantage of this method is the uniform applicability for different data sets compared to a single vertical filtering or to a combination of two sepa- rate filtering techniques in the vertical and in time as usually done for lidar data (e.g., Ehard et al., 2015; Baumgarten et al., 2017). Another advantage compared to Fourier-based methods is that the technique is applicable to unevenly sampled data and data gaps. Further, it is possible to conduct an error propagation of the statistical uncertainties associated to each measurement of the time series.

On a global scale we use a least-squares fit to extract the individual tidal components provided by MERRA-2 according to a separation between migrating and non-migrating thermal tides and to classify the overall tidal structure in the atmosphere. Therefore, Eq. (1) is modified in the following way:

$$
\begin{aligned}
& T_{\text {fil }}, u_{\text {fil }}, v_{\text {fil }}=T_{0}, u_{0}, v_{0}+\sum_{s=-3}^{3} \sum_{n=1}^{2}\left(A_{s n} \cdot \sin \left(s \cdot \lambda-\frac{2 \pi}{P_{n}} \cdot t\right)\right. \\
& \left.+B_{s n} \cdot \cos \left(s \cdot \lambda-\frac{2 \pi}{P_{n}} \cdot t\right)\right),
\end{aligned}
$$

where $s$ and $\lambda$ denote the zonal wave number and the longitude, respectively.

\section{Results}

In the first part of the result section, the total tidal fields containing the diurnal, semidiurnal and terdiurnal component from temperature observations of the lidar will be compared to the tidal fields from temperature and winds obtained by MERRA-2 using the same analysis approach. The second part will be focused on the amplitudes and phases of the different tidal components based on the mean values over the sounding period as well as based on time-resolved values. In the third part, the global fields from MERRA-2 will be investigated with a similar approach to determine which tidal components are seen in the local data.

\subsection{Tidal fluctuations}

Based on the filtering with the ASF the resulting tidal temperature field compared to the total temperature field from the lidar observation is shown in Fig. 1a and b over a sounding period of approximately $10 \mathrm{~d}$ in May 2016 in an altitude range from 30 to $70 \mathrm{~km}$. The large-scale structures from the harmonic analysis reveal a decay between 10 and 11 May, which was already investigated in Baumgarten et al. (2018) using only a one-dimensional spectral filter. But the adaptive spectral filtering leads to more information about the amplitudes and phases in time and space, which is an enhancement compared to using the one-dimensional filtering approach. In addition to the general behavior of the tides, it is clearly seen that the dominating variability in the temperatures is caused by tides. Especially, huge tidal amplitudes are visible in the stratopause region (around $50 \mathrm{~km}$ ), with a very stable phase 
during the sounding. Before a comparison of the temperature with additional wind information from MERRA-2 is made, we show that MERRA-2 data in general capture the same tidal structures as the lidar. Therefore, also the MERRA-2 temperatures are analyzed using the adaptive spectral filter combined with vertical filtering. The temperature field and the filtered temperature field (tides and background) from MERRA-2 are shown in Fig. 1c and d. From the absolute temperatures, it can clearly be seen that in principle the resolved range of temperatures is almost the same in both data sets. But MERRA-2 temperatures are approximately $5 \mathrm{~K}$ less than the lidar temperatures over the whole time (see Fig. 1a and $\mathrm{b}$ at $40 \mathrm{~km}$ altitude). The filtered temperature fields show the same. The underestimated background temperature in MERRA-2 does not affect the temporal evolution of the tidal structures themselves. The tidal structures from the lidar and from MERRA-2 show a good agreement regarding the phase. Some small-scale structures seen in the lidar data are not fully captured by MERRA-2 due to the coarser resolution in time and in the vertical direction of MERRA-2 data compared to the lidar data.

Subtracting the mean background state of the atmosphere from the filtered tidal temperature fields yields the temperature fluctuations only induced by tides. These fluctuations are shown in Fig. 2 for both data sets. Basically, there is a very good agreement between both tidal temperature fluctuations. Because of the slightly better temporal resolution and the better vertical resolution of the lidar data compared to the MERRA-2 data, differences occur mainly for the subharmonic tidal components. Especially at altitudes larger than $60 \mathrm{~km}$, further discrepancies are visible due to the increasing amplitudes in the lidar data, which are not captured by MERRA-2. One reason is that the data assimilation in MERRA-2 is limited at these altitudes, which results in fewer captured tidal features in MERRA-2 compared to the lidar data. Another reason is the sponge layer as the upper boundary in MERRA-2, which also damps wave amplitudes near the model top. But nevertheless, the total tidal variation from the lidar temperatures shown in the figure is in phase with the tidal variation obtained by MERRA-2 almost over the whole altitude range below $60 \mathrm{~km}$. For a closer look, the tidal fluctuations of both data sets are shown together for one particular altitude of $50 \mathrm{~km}$ in Fig. 3. The data sets agree very well in phase, and even the magnitude of the tidal temperature fluctuations is comparable. Aside from the differences mentioned above, the results demonstrate that MERRA-2 provides suitable temperature data for a comparison to lidar data regarding tidal phase studies. From this we assume that the MERRA-2 wind is also related to the realistic winds, although we have not tested this.

The wind data from MERRA-2 are treated in the same way as the temperature data, and tidal wind fluctuations are separately calculated for the zonal and the meridional winds. The tidal wind fluctuations are shown in Fig. 4 for both wind components over the same sounding period and the same altitude range as the lidar data. Clear large-scale structures are visible in the data from both wind components. The total tidal wind fluctuations are mostly dominated by a diurnal signature; this is especially the case for the meridional tidal wind fluctuations. The same behavior was already seen in the temperature fluctuations induced by tides. Below $45 \mathrm{~km}$ as well as above $65 \mathrm{~km}$, a semidiurnal component also occurs in both wind components. While the temperature fluctuations induced by tides are on the order of a few kelvin (relative temperature change of $\sim 1 \%$ ), the wind fluctuations are in the range of $10 \mathrm{~m} \mathrm{~s}^{-1}$ (relative wind change of $\sim 30 \%$ ), so the response of the wind on tides is larger compared to the temperature response. This agrees very well to the amplitudes of $2.5 \mathrm{~K}$ for the temperature tide and $8 \mathrm{~m} \mathrm{~s}^{-1}$ for the wind tides $(u, v)$ from the modeled Hough functions for the diurnal component (Lindzen, 1967). The results for the concrete tidal amplitudes and phases will be presented in the next subsection.

\subsection{Amplitudes and phases}

For the determination of the phase relation between the tidal temperature and the tidal wind fields, we first compare the amplitudes and phases as a mean over the $10 \mathrm{~d}$ in May 2016 in an altitude range between 30 and $70 \mathrm{~km}$. The amplitudes for the diurnal, semidiurnal and terdiurnal tide are shown in Fig. 5. The amplitudes from the temperature field are derived using the lidar data as well as the data from MERRA2. In principle, both data sets reveal similar amplitudes for all three tidal temperature components. Larger differences only occur for the terdiurnal component at altitudes above $55 \mathrm{~km}$, where the amplitudes from the lidar temperature show a strong increase in contrast to the amplitudes from the MERRA-2 temperatures.

As already seen from the fluctuations themselves, the amplitudes derived from the wind fields are much larger compared to those from the temperature field. A direct comparison of the amplitudes is made from the relative change according to the mean background temperature and the mean background wind. Such comparison reveals a tidal temperature response of only $\sim 1 \%$ and a tidal wind response of $\sim 30 \%$. This strong wind response is in particular the case for the diurnal component above $45 \mathrm{~km}$ altitude, while, for example, the terdiurnal component is comparably weak in the winds over the whole altitude range. For this component there is even a stronger increase in the amplitude from the temperature visible for altitudes above $60 \mathrm{~km}$ compared to those from the winds, although the values are underestimated in this altitude range. However, the amplitudes are much smaller than from the diurnal and semidiurnal component. The diurnal wind tide is the dominating tidal component in an altitude range between 45 and $65 \mathrm{~km}$, while the semidiurnal wind tide shows a strong decrease around $60 \mathrm{~km}$; this is completely different for temperature tides. Here, the amplitudes of the diurnal temperature tide show an increase 

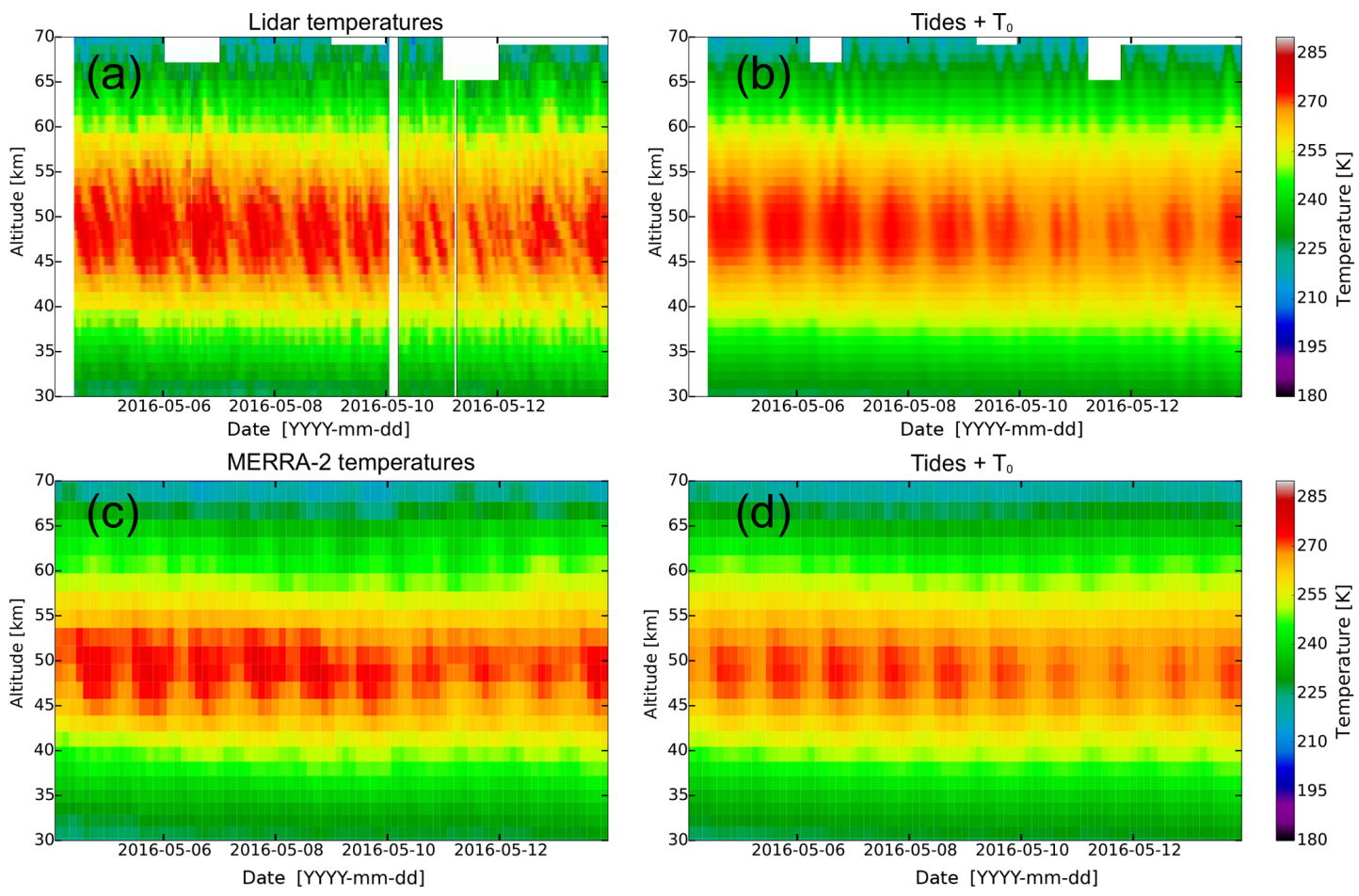

Figure 1. Temperatures and filtered temperature field including tides and background observed by the RMR lidar at Kühlungsborn on 4-13 May 2016 (a, b), and the corresponding data obtained by MERRA-2 (c, d).
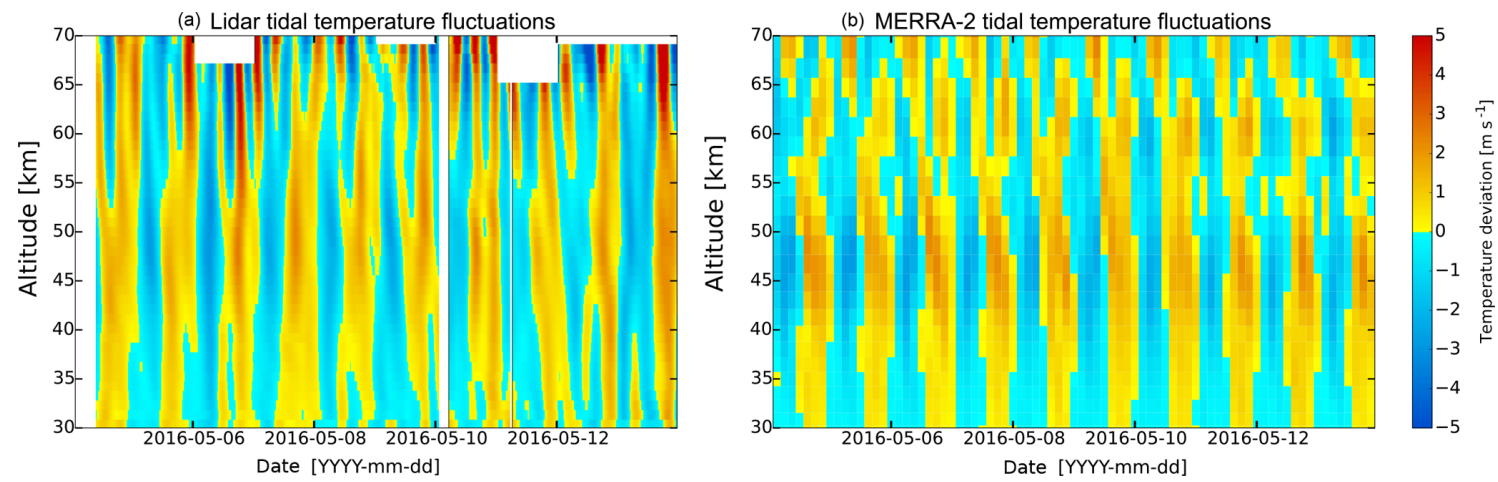

Figure 2. Tidal temperature fluctuations from the lidar (a) and from MERRA-2 (b) on 4-13 May 2016.

up to almost $2 \mathrm{~K}$ at $50 \mathrm{~km}$ altitude, while the amplitudes fall off again to values around $1 \mathrm{~K}$ between 60 and $65 \mathrm{~km}$. This behavior is also evident for the amplitudes derived from the MERRA-2 temperatures. As the results of the temperature tides are comparable from the lidar and MERRA-2, further descriptions of the temperature tide always refer to the lidar data. The semidiurnal temperature tide instead is almost constant with altitude and shows only a slow increase up to $2 \mathrm{~K}$ above $55 \mathrm{~km}$. Furthermore, the strength of the diurnal wind tide gets weaker above $60 \mathrm{~km}$; this is the altitude range where the semidiurnal wind tide shows an increase. For the MLT region it is already known that the semidiurnal tide is the dominating tide, which is also indicated from the study here.

The mean tidal phases are shown in Fig. 6 in the same way as the amplitudes for the diurnal, the semidiurnal and the terdiurnal component derived from the temperature field and the wind fields. The mean phase of the diurnal tidal signature is nearly constant with altitude from the lidar temperatures as well as from the winds. Between the zonal and meridional tidal wind component, a constant phase shift of around $-6 \mathrm{~h}$ is visible for the whole altitude range above $45 \mathrm{~km}$. This corresponds to a phase shift of $-90^{\circ}$ for the diurnal tide. The phase shift between the diurnal temperature tide and the diurnal zonal wind tide is almost zero up to an altitude range 


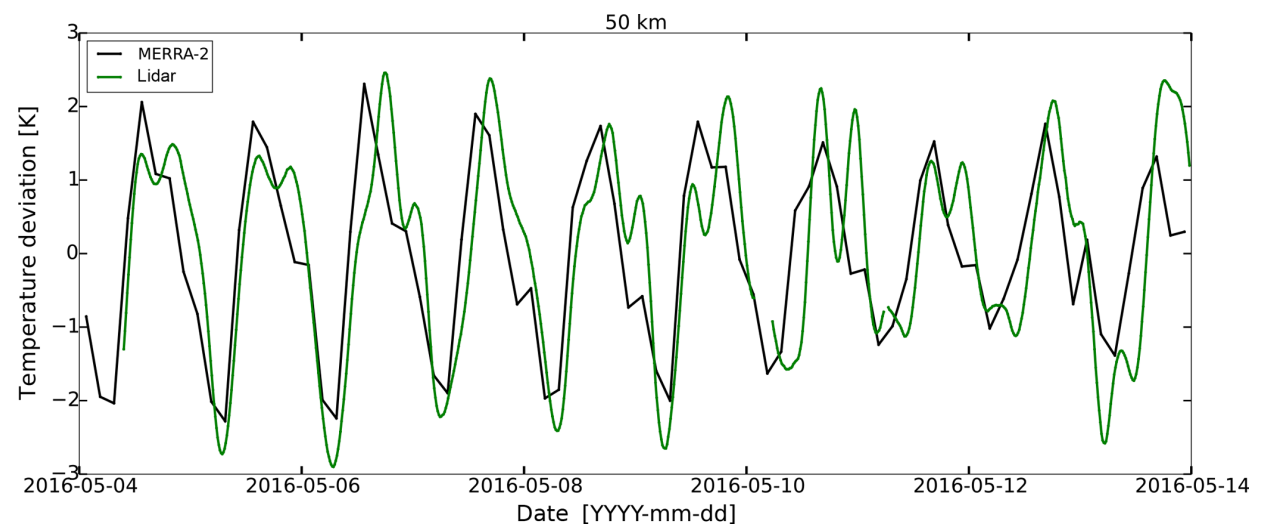

Figure 3. Comparison of tidal temperature fluctuations from the lidar (green) and MERRA-2 data (black).
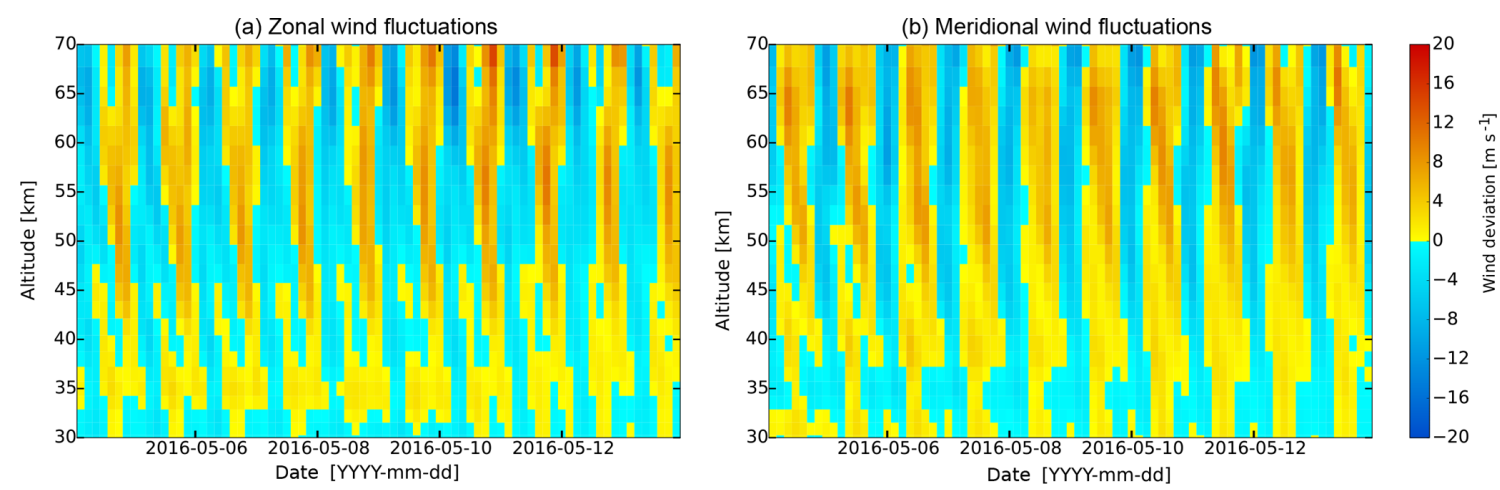

Figure 4. Tidal fluctuations derived from the zonal (a) and meridional winds (b) given by MERRA-2 for the same period in May 2016.

of $55 \mathrm{~km}$. For larger altitudes as well as for altitudes lower than $35 \mathrm{~km}$ the phase of the temperature tide decreases because of the small amplitude of the diurnal signature in the temperature. These are regions where a harmonic analysis is not well determined. The results for the semidiurnal component look different compared to the diurnal tidal phases. The semidiurnal tidal phases of both wind components increase with larger altitudes, but both wind components show a phase jump around 40 and $47 \mathrm{~km}$ for $v$ and $u$, respectively. These jumps are the explanation for the visible semidiurnal tidal component in the total tidal wind fluctuations at lower altitudes (see Fig. 4). Due to the changing phase, the semidiurnal variation is shifted and less visible. The meridional semidiurnal wind tide leads the zonal one with $3 \mathrm{~h}$, which corresponds to a phase shift of, again, $90^{\circ}$ in an altitude range between 30 and $40 \mathrm{~km}$ and between 50 and $57 \mathrm{~km}$. The information from larger altitudes is not taken into account due to its reduced reliability. Between 40 and $50 \mathrm{~km}$ the phase shift of zonal and meridional semidiurnal tidal winds is almost $12 \mathrm{~h}$, which means that both components are in phase. The phase of the semidiurnal temperature tide shows a slow decrease from 14 to $12 \mathrm{~h}$ up to $50 \mathrm{~km}$ altitude. Beyond that, the phase increases again and stays constant at $15 \mathrm{~h}$ above $55 \mathrm{~km}$. A fixed phase relation to the wind components can only be given between
50 and $57 \mathrm{~km}$ altitude with $6 \mathrm{~h}\left(\right.$ or $\left.180^{\circ}\right)$ between the temperature tide and the meridional wind tide.

The mean phases of the terdiurnal tidal component are almost constant with altitude from the temperature as well as from the wind field. The phase shift between the zonal and meridional wind tide slightly varies around $-2 \mathrm{~h}\left(-90^{\circ}\right)$. Therefore, the meridional wind leads the zonal wind tide in the same way as seen for the other tidal components. At 39 and $55 \mathrm{~km}$ the phases of all components become equal. Especially for lower altitudes, the amplitude of the terdiurnal wave component is very small, which causes larger difficulties and uncertainties in the fitting algorithms, yielding a zero phase shift between the temperature and the wind tide. In general, the mean phases reveal a fixed phase relation between both wind components and a semi-fixed phase relation between the temperature and the zonal wind tide. For the sake of completeness, a comparison between the temperature tide derived from the lidar and from MERRA-2 was also done based on mean amplitudes and mean phases. In principle, both temperature tides show the same behavior with an almost zero phase shift, which makes a comparison of these data sets possible.

As these results are only based on mean values, the next step is to show the time-resolved amplitudes and phases de- 

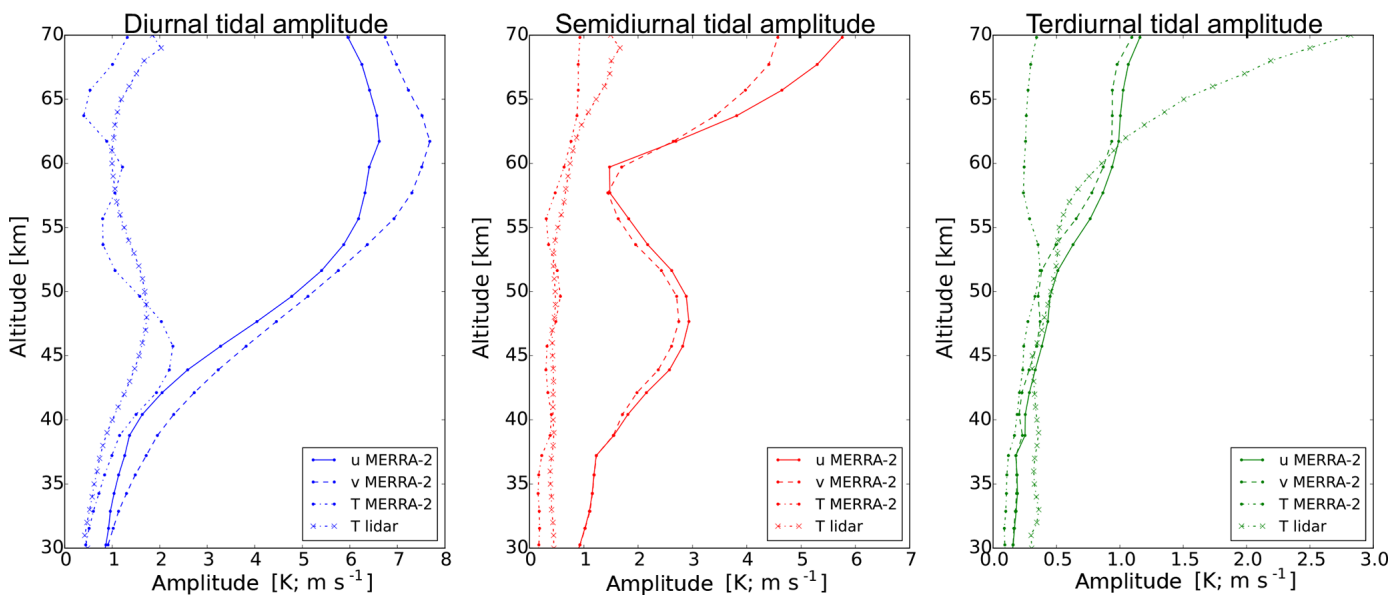

Figure 5. The diurnal (blue), the semidiurnal (red) and the terdiurnal (green) tidal amplitudes derived from the lidar temperature field (dotted line with crosses), from the MERRA-2 zonal wind field (solid line) and from the meridional wind field (dashed line) as mean over all days of the sounding period in May 2016. For comparison the tidal amplitudes from the temperature field of MERRA-2 are also shown (dotted line with points).
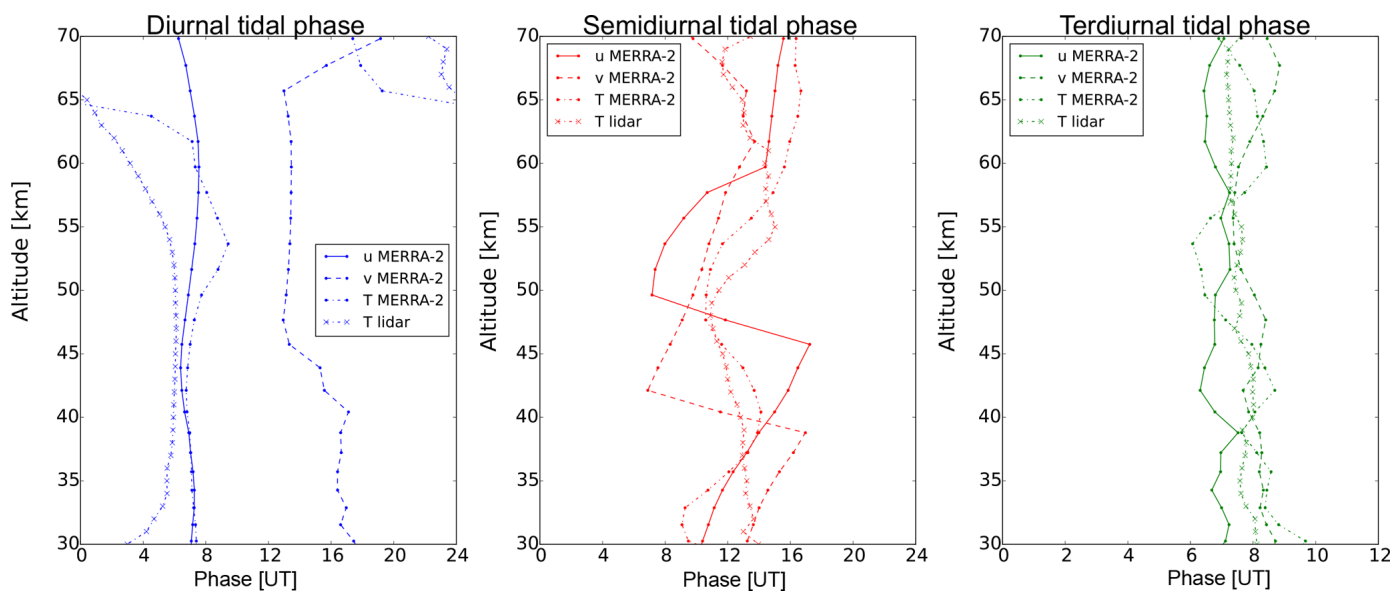

Figure 6. The diurnal (blue), the semidiurnal (red) and the terdiurnal (green) tidal phases derived from the lidar temperature field (dotted line with crosses), from the MERRA-2 zonal (solid line) and from the meridional wind field (dashed line) as mean over all days of the sounding period in May 2016. Please note the different $x$ scale for the terdiurnal tidal phase. For comparison the tidal phases from the temperature field of MERRA-2 are also shown (dotted line with points).

rived with the adaptive spectral filtering. Each tidal component is separately shown in the following figures, but the amplitudes and phases from the temperature tide and from the zonal and the meridional wind tide are shown together for a better direct comparison. First of all, we focus on the diurnal tidal components, which are shown in Fig. 7. The amplitudes from both wind components grow with larger altitudes during the whole sounding period (Fig. 7e, g), which is excepted due to the decreasing air density and the conservation of energy. Contrary to this, the tidal amplitude from the temperature data shows a saturation and even a decrease above $55 \mathrm{~km}$. This is evident in the lidar data as well as in the MERRA-2 data (Fig. 7a, c). While the amplitude also decreases with time from the lidar temperatures and even for the MERRA-2 temperature data, the wind tides stay constant with time except for a small periodic oscillation. The amplitude of the meridional wind tide is larger than that of the zonal wind tide by a factor of around 1.3 for altitudes below $60 \mathrm{~km}$. From the time-resolved phases (Fig. 7f, h) it can be clearly seen that the phase shift between the zonal and meridional wind is around $-6 \mathrm{~h}$ (the meridional wind tide leads the zonal wind tide) during the whole sounding. The diurnal temperature tide shows a similar phase progression to the diurnal zonal wind tide (Fig. 7b, d, f). Differences from this phase relation mainly occur for the lidar data for altitudes larger than $60 \mathrm{~km}$ as well as at low altitudes around $35 \mathrm{~km}$, while the MERRA-2 temperature tide matches the phase of the zonal wind tide. These differences can be explained by a 
different temporal and vertical resolution of the data sets and limitations in data assimilation.

The time-resolved amplitudes and phases of the semidiurnal tidal signature are shown in Fig. 8 in the same way as for the diurnal tidal component. As already seen from the diurnal amplitudes, also the semidiurnal tides are more visible in the wind data than in the temperature data. But now for the semidiurnal tide, the amplitude of the zonal wind tide is slightly larger than that of the meridional wind tide. The ratio of the meridional and the zonal wind amplitude is around 0.8. Further differences to the diurnal tidal component are seen from the altitude growing and the temporal variation. The semidiurnal tidal amplitude from the temperature data increases with altitude (Fig. 8a), while this is not the case for the wind components. Here, the amplitudes drop down between 55 and $60 \mathrm{~km}$ (Fig. 8e, g). In this altitude range also the phases are not stable due to amplitudes of the semidiurnal component that are too small. But nevertheless, between where no phase jumps occur, the phases slowly vary with time. The phase difference between the zonal and the meridional wind tide changes over the altitude. There are ranges where both components are almost in phase due to a phase jump or where both components have a phase shift of $-3 \mathrm{~h}$. This is visible, for example, at $45 \mathrm{~km}$ (phase shift of $10 \mathrm{~h}$, which means almost in phase) or at $35 \mathrm{~km}$ (phase shift of $\left.-90^{\circ}\right)$.

The results for the terdiurnal tidal component (Fig. 9) look even more complicated, as the overall variation is smaller than for the diurnal and semidiurnal component; therefore, a robust phase determination is more difficult. Due to this circumstance a phase determination has a larger error. The amplitude of the zonal wind tide is a little bit larger than that of the meridional wind tide (Fig. 9e, g). The ratio of the meridional to the zonal amplitude is about 0.7 . But in general, the same temporal variation is visible for both wind tides. The overall phase variation is around $\pm 4 \mathrm{~h}$, which causes the impression of more phase jumps over time than for the other tidal components, as the overall variation was smaller for the other components. The phase difference between the zonal and meridional terdiurnal tide is constant at about $-2 \mathrm{~h}$ during the whole sounding. So a fixed phase shift of $-90^{\circ}$ between the wind components is still valid. The terdiurnal temperature tide is in phase with the zonal wind tide for certain times and altitudes, especially for the first days of the sounding. During the last days the phase of the temperature tide shifts to the meridional wind tide.

A comparison between the tidal results derived from the lidar temperatures and the MERRA-2 temperatures shows in general a good agreement. The decrease in the diurnal tidal amplitudes with time is also visible in MERRA-2 but is not as strong as in the lidar data (Fig. 7a, c). However, the amplitudes are in the same range for both data sets. The temporal variation in the amplitudes seen in the lidar data is not fully captured by MERRA-2, but the basic features are comparable, e.g., amplitude saturation of the diurnal tide above
$55 \mathrm{~km}$. The time-resolved phases of the lidar temperature tides and the MERRA-2 temperature tides roughly agree over the $10 \mathrm{~d}$ period in May 2016. The phase progression in general indicates that the tidal phase is not constant over time, as even in MERRA-2 data the phases show a small variation with time. This needs to be further investigated during the whole year or at least for other seasons; this will be done in another study, as this is out of the scope of this paper.

\subsection{Tidal modes from MERRA-2 global fields}

MERRA-2 also provides global fields of temperature and winds in the atmosphere. Those fields are used to determine which tidal modes are observed at the ground with local lidar measurements. Therefore, the global fields are filtered by applying the adaptive spectral filter including the zonal wave number and longitude (Eq. 3) to the data. The resulting amplitudes for the migrating diurnal and semidiurnal tide (DW1 and SW2) are shown in Figs. 10 and 11, respectively. The nomenclature follows Oberheide et al. (2015). The diurnal migrating tide (DW1) shows in principle the same strength and the same altitudinal structure from the global fields as from the local perspective (Fig. 7). There is a localized maximum of amplitudes in the temperature field at altitudes around $45 \mathrm{~km}$, while the tidal wind amplitudes show an increase with altitude instead. A similar agreement with the local data is found for the semidiurnal migrating tide (SW2). Due to the coarser temporal resolution of the global fields, the short-term variation in both tidal components is not captured. However, the good agreement of these two single tidal components to the local data indicates that the observations are dominated by single tidal waves.

A comparison of these two components to other potential tidal components derived for the location of the lidar station at Kühlungsborn during May 2016 is shown in Fig. 12 at an altitude of $45 \mathrm{~km}$. It is clearly visible that the DW1 is the most dominating tidal component over the whole time period. The amplitudes of the non-migrating tides as well as of the zonally symmetric tide are smaller than $1 \mathrm{~K}$ and therefore insignificant compared to the DW1 tide. The same appears for the semidiurnal tide, although this component is generally weaker than the diurnal component. The amplitudes of potential other diurnal and semidiurnal tidal components including the zonally symmetric and non-migrating tides separated for each wave number are shown in Appendix A.

\section{Discussion}

This paper addresses the relationship between tidal fluctuations observed in temperatures and winds in the stratosphere and mesosphere during $10 \mathrm{~d}$ in May 2016 using the ground-based, daylight-capable RMR lidar located at Kühlungsborn $\left(54^{\circ} \mathrm{N}, 12^{\circ} \mathrm{E}\right)$ together with reanalysis data provided by MERRA-2. A similar study was done by She et al. 

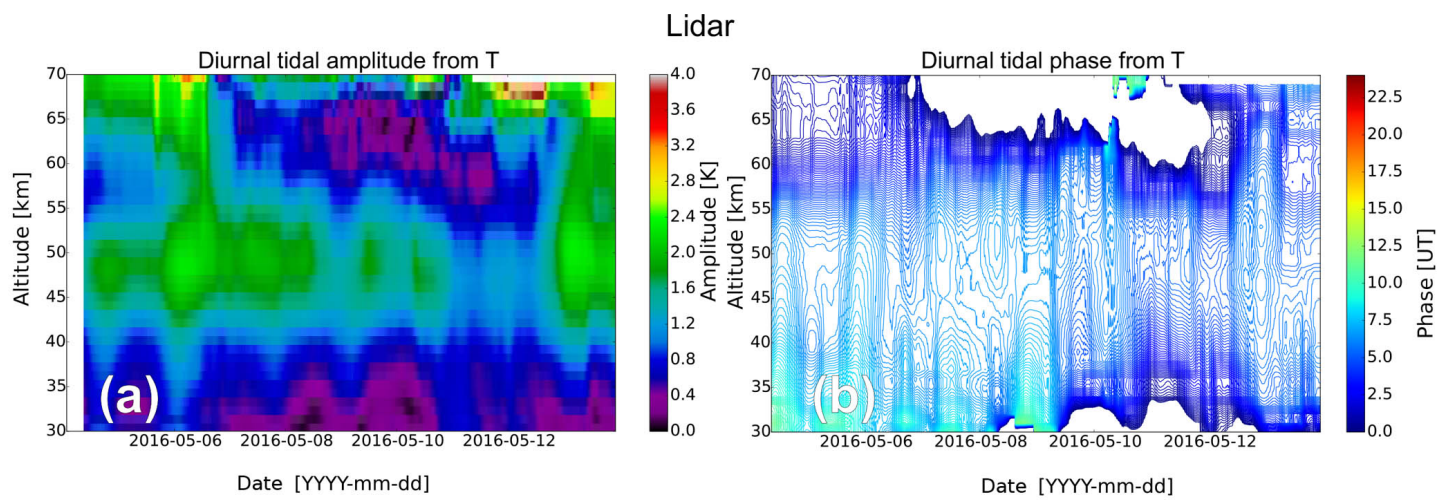

MERRA-2
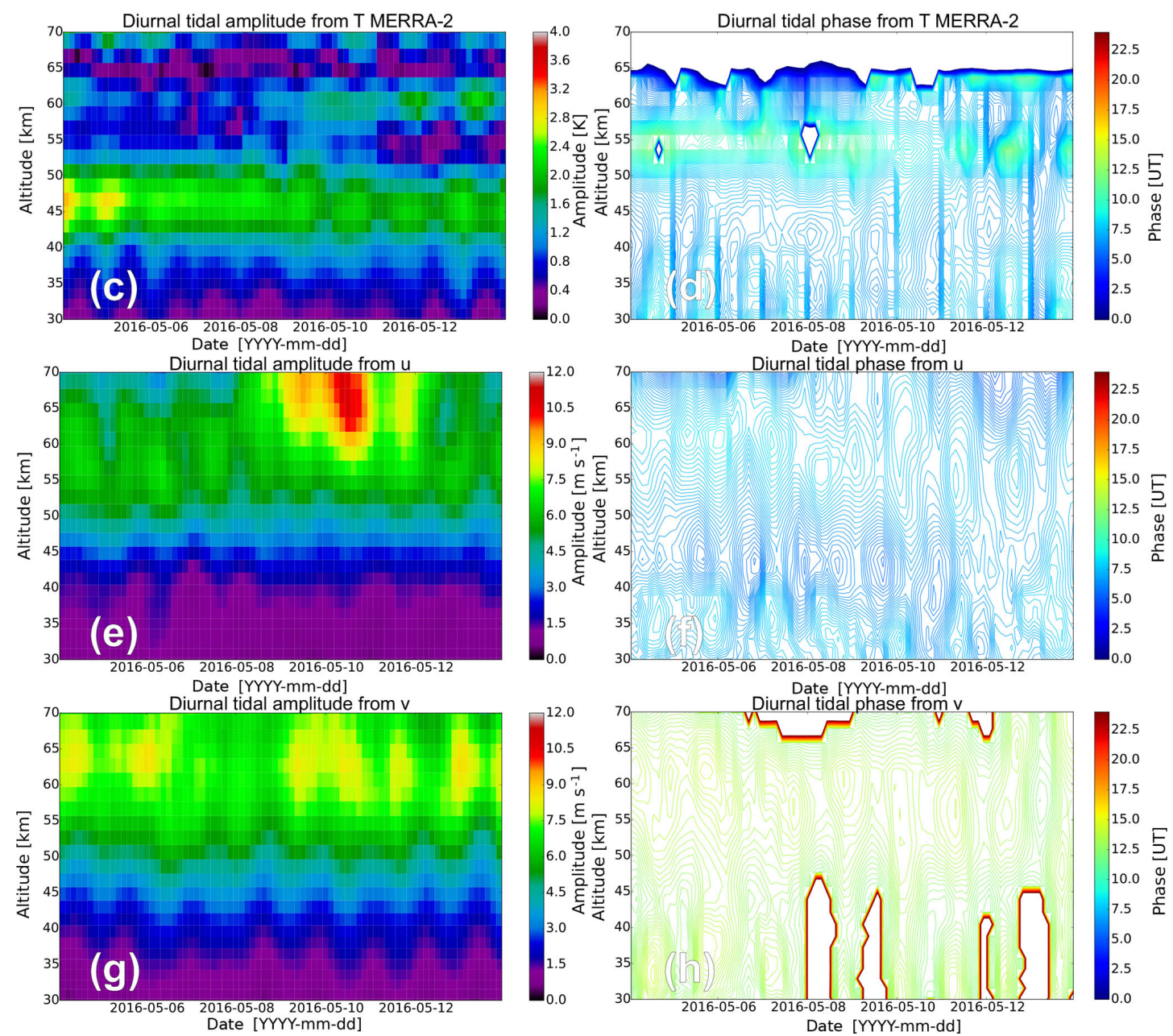

Figure 7. Comparison of the time-resolved diurnal tidal amplitudes $(\mathbf{a}, \mathbf{c}, \mathbf{e}, \mathbf{g})$ and phases $(\mathbf{b}, \mathbf{d}, \mathbf{f}, \mathbf{h})$ derived from the lidar and MERRA-2 temperature field and the MERRA-2 zonal and meridional wind field in May 2016.

(2016), focusing on the MLT region at Fort Collins $\left(41^{\circ} \mathrm{N}\right.$, $\left.105^{\circ} \mathrm{W}\right)$. They used a Na lidar combined with model predictions from the Climatological Tidal Model of the Thermosphere (CTMT) based on the Hough mode extension (HME) technique to investigate the polarization relation of the di- urnal and semidiurnal tide. They derived the polarization relations for tides from the primitive equations for largescale waves (Holton, 2004). Following this study, the derived polarization relation between the temperature and the zonal wind tide is equal to that for the low-frequency grav- 

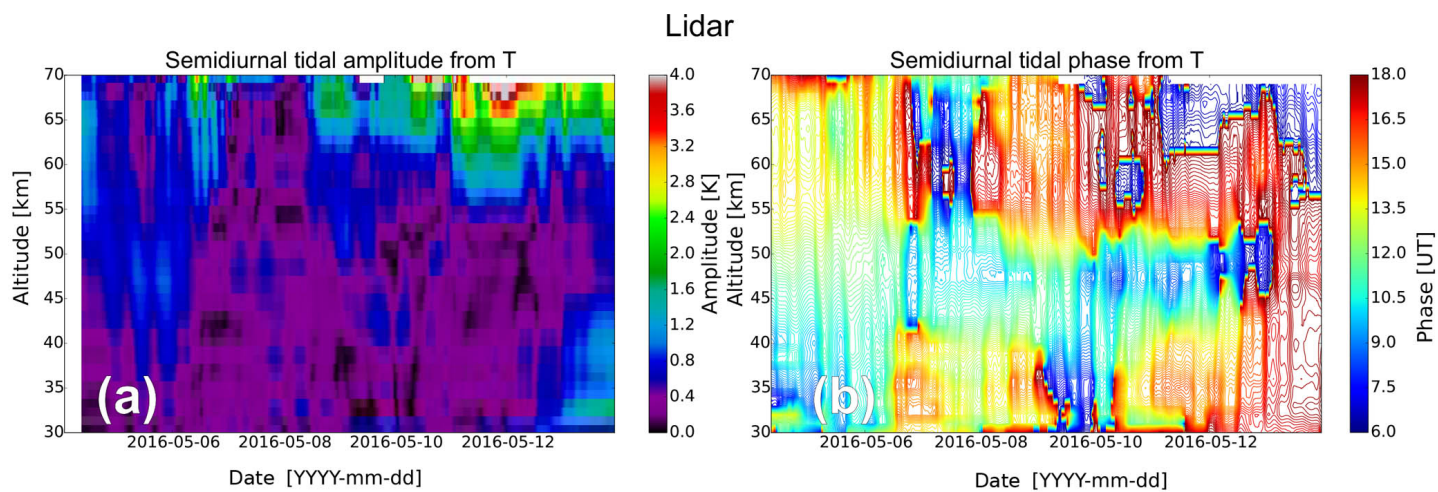

MERRA-2
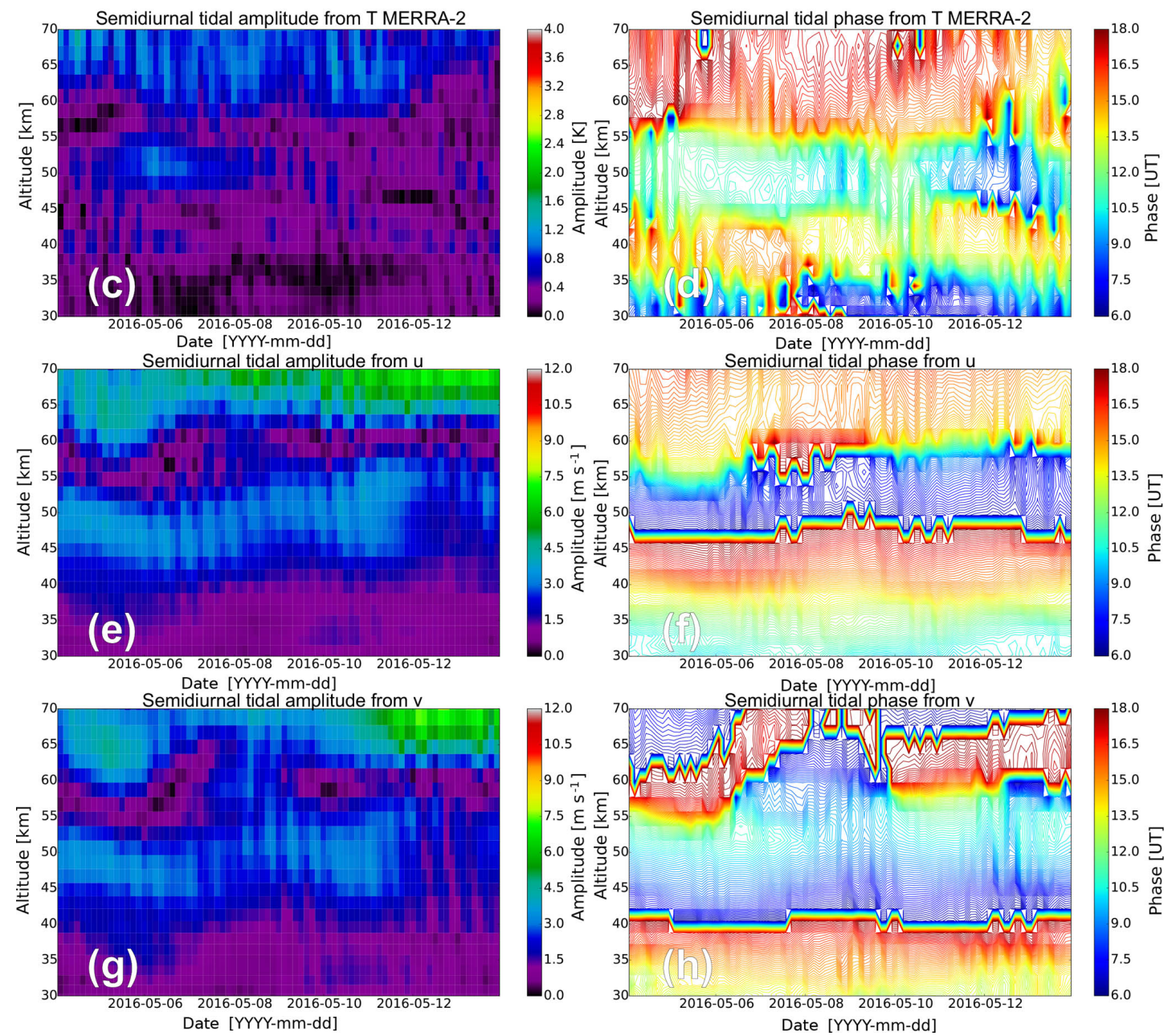

Figure 8. Same as Fig. 7 but for the semidiurnal tidal signature.

ity waves (Hu et al., 2002). The polarization relation between the meridional and the zonal wind tide becomes even simpler by assuming just a single migrating wave (She et al., 2016):

$\widetilde{v}=-i \frac{f}{\widehat{\omega}} \widetilde{u}$, with $f$ as the Coriolis frequency and $\widehat{\omega}$ as the intrinsic frequency of the tidal component. With this equation a ratio of the tidal meridional and zonal wind amplitudes is theoretically known. For a latitude of $54^{\circ} \mathrm{N}$ this ratio is 1.6 and 0.8 for the diurnal and semidiurnal tidal component, respectively. The results of our analysis are in very good agreement 


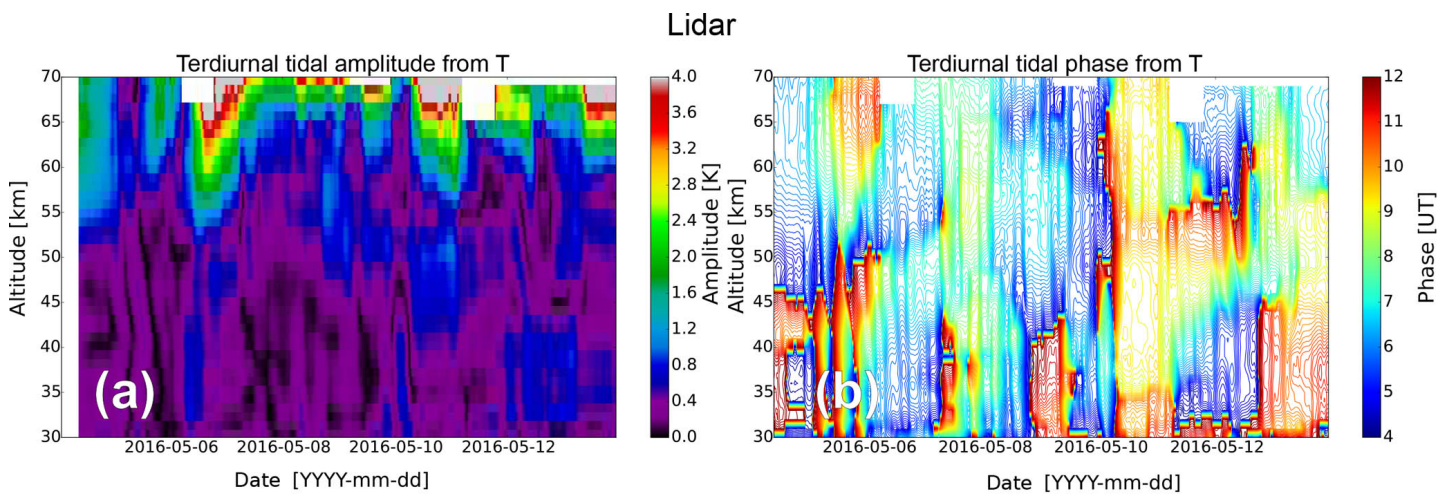

MERRA-2
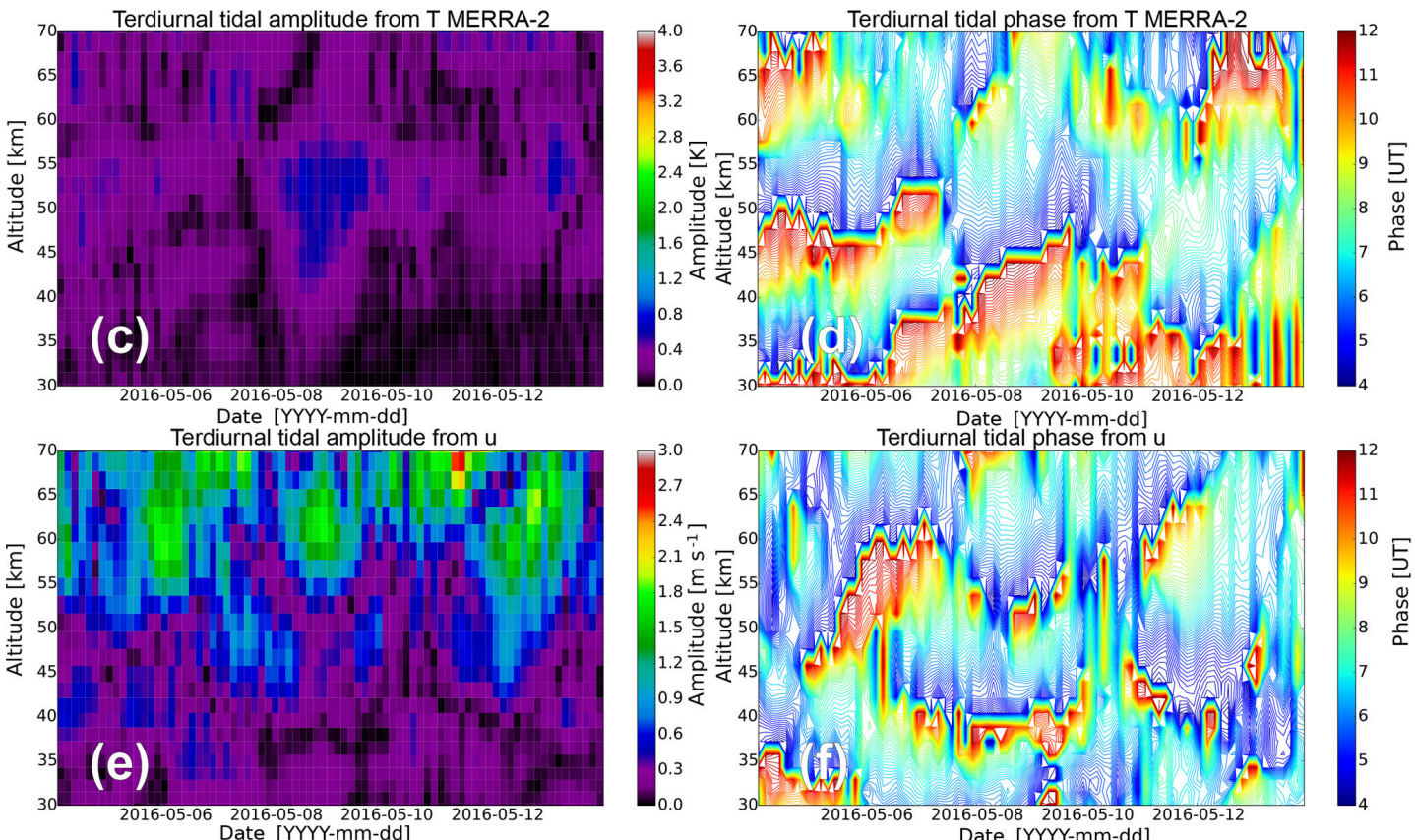

Terdiurnal tidal amplitude from $v$
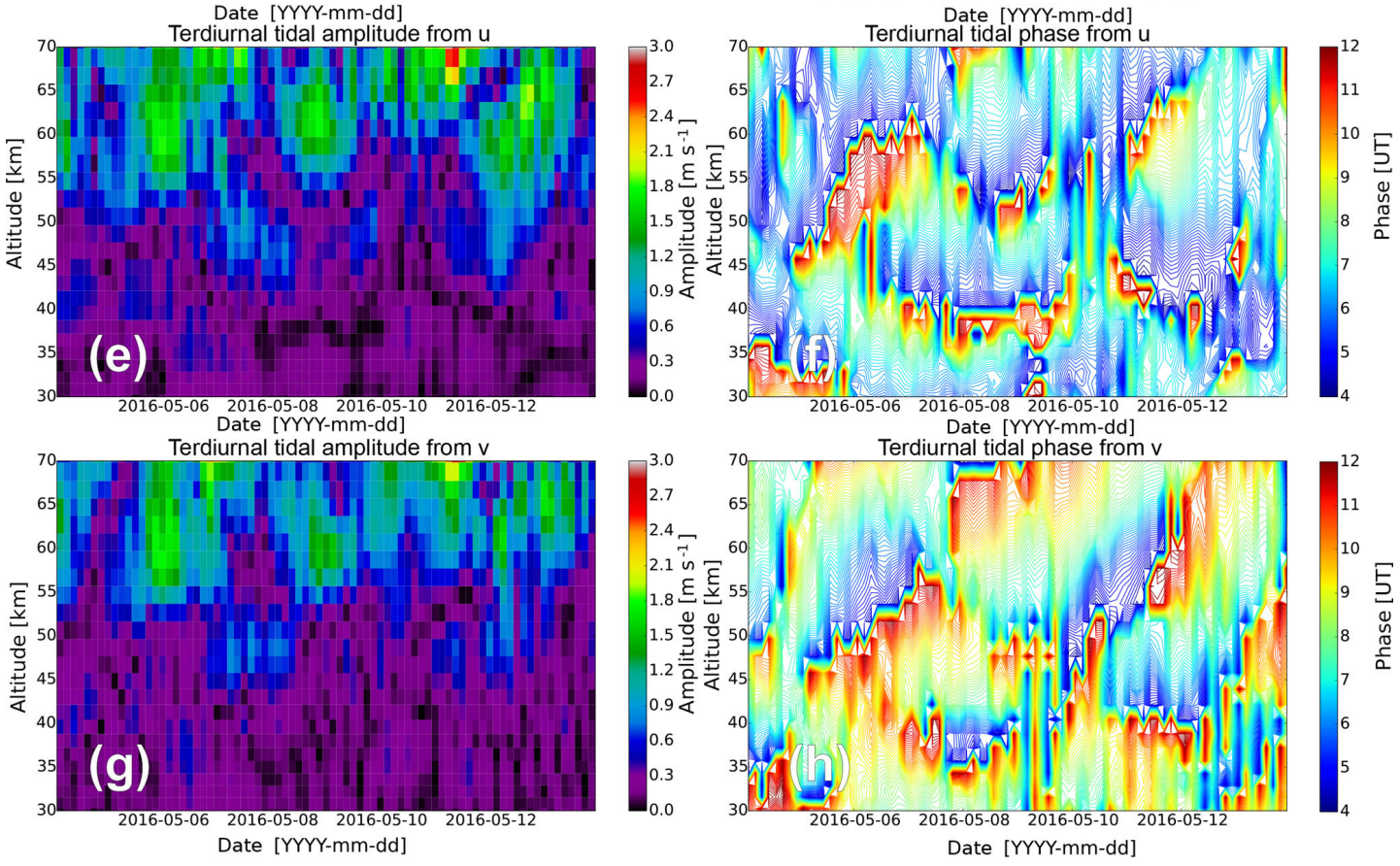

Figure 9. Same as Fig. 7 but for the terdiurnal tidal signature. Note the different color scale for the phases, compared to Figs. 7 and 8.

with these values. This suggests that the tidal waves from MERRA-2 are dominated by the migrating tide, and nonmigrating tidal modes only show a negligible contribution during the evaluated period. Additionally, the global analysis of MERRA-2 temperature and wind fields also showed a dominance of the diurnal and semidiurnal migrating tide (see Figs. 10, 11 and 12), which confirms the result derived using the ratio of zonal and meridional tidal wind amplitudes. Smaller differences to the values expected are basically due to the simplifications in deriving the relation between the meridional and zonal tide, as there is neither a latitudinal background temperature gradient nor a dissipation 

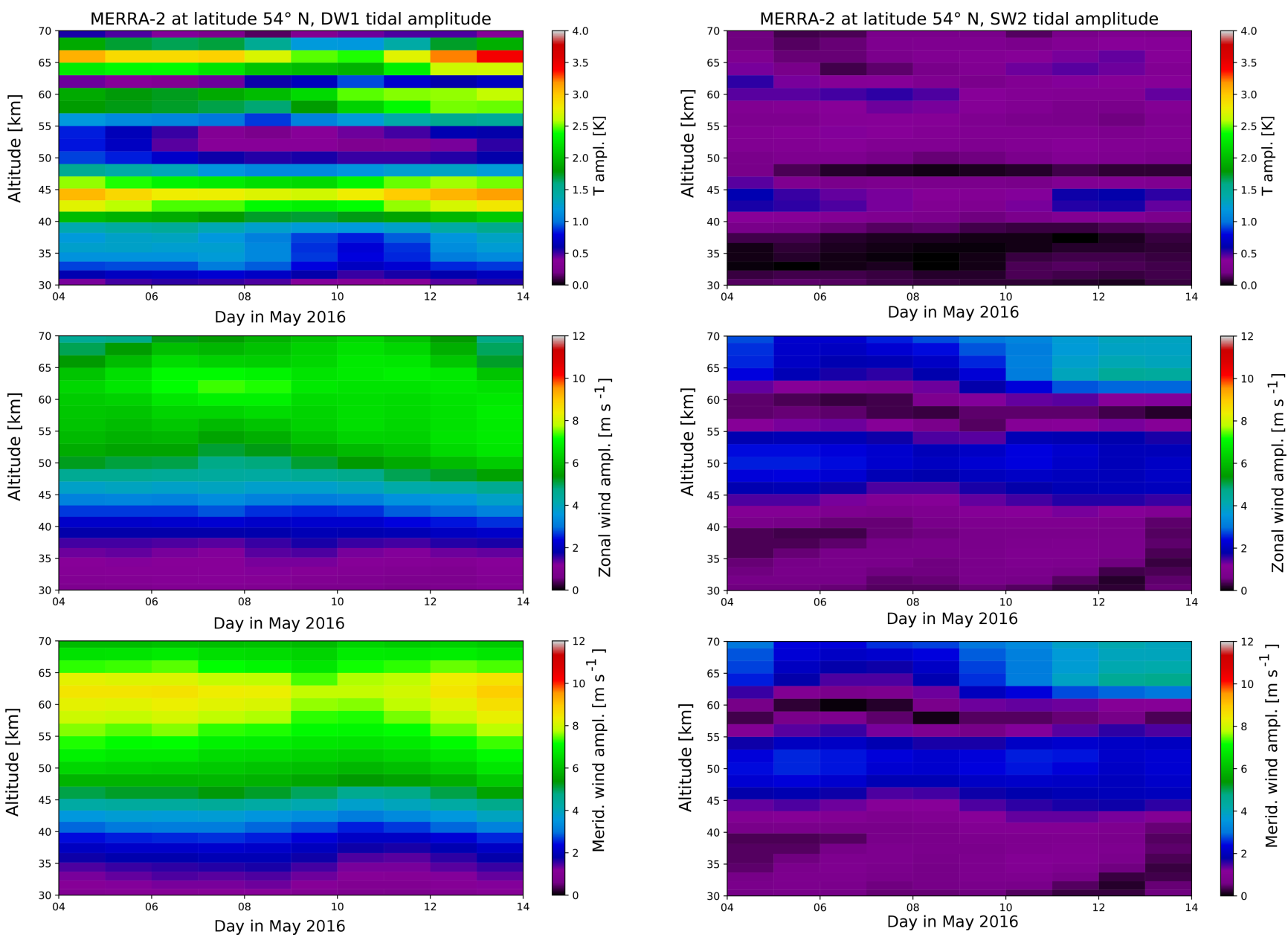

Figure 10. DW1 amplitude in temperature, zonal and meridional wind from global MERRA-2 fields at the latitude of $54^{\circ} \mathrm{N}$.

included. In addition to this, the altitude range covered with the lidar and MERRA-2 includes source regions of tidal excitation as well as regions where trapped tidal modes can exist (Forbes and Garrett, 1979; Forbes and Hagan, 1988; Yuan et al., 2010; Kopp et al., 2015). However, the general behavior of the tidal signatures is in agreement with the theoretical expectations.

The wind tides from MERRA-2 and the temperature tide from the lidar showed that there is a fixed phase relation between both wind components and a semi-fixed phase relation between the temperature tide and the winds. Typically, observations are limited either to a detection of temperatures or winds. Tidal information based on both quantities was simultaneously derived in the past from model outputs, e.g., from the Kühlungsborn Mechanistic General Circulation Model (KMCM) by Becker (2017). This study addresses the heat budget of the mesosphere and lower thermosphere regarding upward-propagating thermal tides. Therefore, also the mean wind tides were shown together with the mean temperature tide for January and July at $52^{\circ} \mathrm{N}$. From the July data, it is

Figure 11. SW2 amplitude in temperature, zonal and meridional wind from global MERRA-2 fields at the latitude of $54^{\circ} \mathrm{N}$.

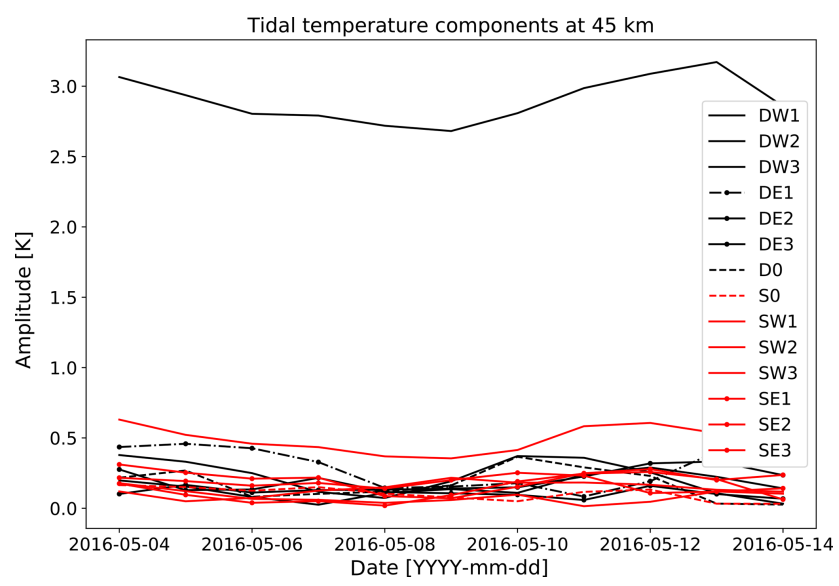

Figure 12. Tidal temperature modes at $45 \mathrm{~km}$ altitude from global MERRA-2 fields at the latitude of $54^{\circ} \mathrm{N}$.

clearly visible that the mean zonal wind tide is phase shifted with $-90^{\circ}$ to the mean meridional wind tide. This is exactly what we observed from the tidal analysis of the winds pro- 
vided by MERRA-2. In Becker (2017) the mean temperature tide from KMCM is shown as total tidal variation. Hence, a direct comparison of the amplitudes for each tidal component is not suitable. But from the KMCM temperature tide itself, an altitude dependence of the dominating tidal component is observable. Above $70 \mathrm{~km}$ Becker (2017) found a stronger semidiurnal component compared to the lower altitudes, where a diurnal component dominates. This transition from a diurnal to a semidiurnal tidal component is also indicated in the lidar data, above an altitude of $60 \mathrm{~km}$ above Kühlungsborn, from this study (see Fig. 2). Such a development is also known from other studies (e.g., Smith, 2012; Pokhotelov et al., 2018). Aside from the fact that the amplitudes from KMCM cannot be compared directly to our data, a general phase relation between the temperature tide and the wind tide from KMCM can still be derived for comparison. The temperature tide follows mainly the mean zonal wind tide in KMCM for altitudes below $50 \mathrm{~km}$, which is confirmed by our data. Above $50 \mathrm{~km}$ altitude, a phase shift of $180^{\circ} \mathrm{oc}-$ curs in the KMCM data. This agrees with the semidiurnal tidal component from our study, and the diurnal tidal component also shows a larger phase shift to the zonal wind tide from MERRA-2 above $50 \mathrm{~km}$.

The explanation for the changing phase with growing altitude is directly written in the derived phase relation between the temperature tide and the zonal wind tide provided by She et al. (2016). The relation of both quantities is highly dependent on the vertical wavelength and the period. The latter is fixed for each tidal component, but the vertical wavelengths are not constant with altitude. The main reason for this is wind filtering and dissipation. The altitude dependence of the vertical wavelength or the vertical wave number can be in principle determined from the phase profiles. But the time-resolved phases showed a large temporal variability. This temporal tidal phase variation due to an intermittency in the tidal excitation is taken into account with the ASF, while other analysis methods assume a constant phase at least for the migrating tide. This has an impact on the interpretation of the significance of migrating and non-migrating tides. But solely from the observed temporal variability, we claim that this behavior has to be taken into account when tidal information is calculated from, for example, satellite data. As those instruments need large time intervals in covering a day at one location, they typically assume a constant phase of the tides. Our investigations address this issue and demonstrate that even for the diurnal tidal component the phase is not stable over $10 \mathrm{~d}$ of observation. Therefore, we suggest that the phase shows a drift of several hours over the whole year and further phase jumps occur during special occasion. Using MERRA-2 wind data next to the available lidar data, we will be able to provide further information about tides and the phase relations between the temperature and the wind tide during different seasons, which will enhance our knowledge about the dynamics in the atmosphere. This will be addressed in a future paper.

\section{Conclusions}

The phase relation from tidal signatures in temperatures and winds using lidar and reanalysis data was studied to reveal if both tidal fields have a fixed phase relation. Therefore, an outstanding temperature data set obtained by the RMR lidar located at midlatitudes in Kühlungsborn was used in combination with reanalysis data of MERRA-2. This provides the necessary wind data in the same altitude range as the lidar data. The main results are the following:

1. MERRA-2 temperatures show in principle good agreement with the lidar temperatures. Tidal amplitudes and phases are comparable. The main differences occur for the terdiurnal tidal component. Due to the higher temporal and vertical resolution of the lidar, this instrument captures the terdiurnal component much better than MERRA-2. However, additional wind information provided by MERRA-2 is suitable for being used in a comparison of temperature and wind tides.

2. There is a fixed phase relation between the zonal and meridional tidal wind fluctuations. The meridional wind fluctuations lead the zonal wind fluctuations with a phase shift of $90^{\circ}$. This appears to be constant for all altitudes.

3. There is no fixed phase relation between the temperature and wind fluctuations over the whole altitude range. But nevertheless, a phase relation exists within certain altitude levels. The phase shift between tidal temperature fluctuations and wind fluctuations is strongly dependent on altitude and period. The relation follows the polarization relation of low-frequency gravity waves. If the vertical wavelength and the period are extracted from the data, a known tidal field can be transferred into another tidal field.

4. The global analysis of MERRA-2 confirms that the tidal temperature and wind field locally seen are dominated by the migrating diurnal and migrating semidiurnal tide, if an intermittency of the wave field is taken into account, while other tidal components are negligible.

This analysis complements studies using resonance lidar measurements combined with modeling results in the MLT region. This knowledge will be used in future to deduce an unknown tidal field from another observed tidal field and will enhance the data coverage from single observations.

Data availability. The MERRA-2 data provided by the Global Modeling and Assimilation Office (GMAO) at NASA Goddard Space Flight Center were acquired through the NASA GES DISC online archive. The lidar data are locally archived at the IAP and available upon request from the author. 


\section{Appendix A: Tidal components from the global MERRA-2 fields}

In addition to Figs. 10 and 11 here we provide the results for the stationary diurnal and semidiurnal tide (D0, S0) as well as for the westward- and eastward-propagating non-migrating tidal components (DW2, DW3, SW1, SW3, DE1, DE2, DE3, SE1, SE2 and SE2).
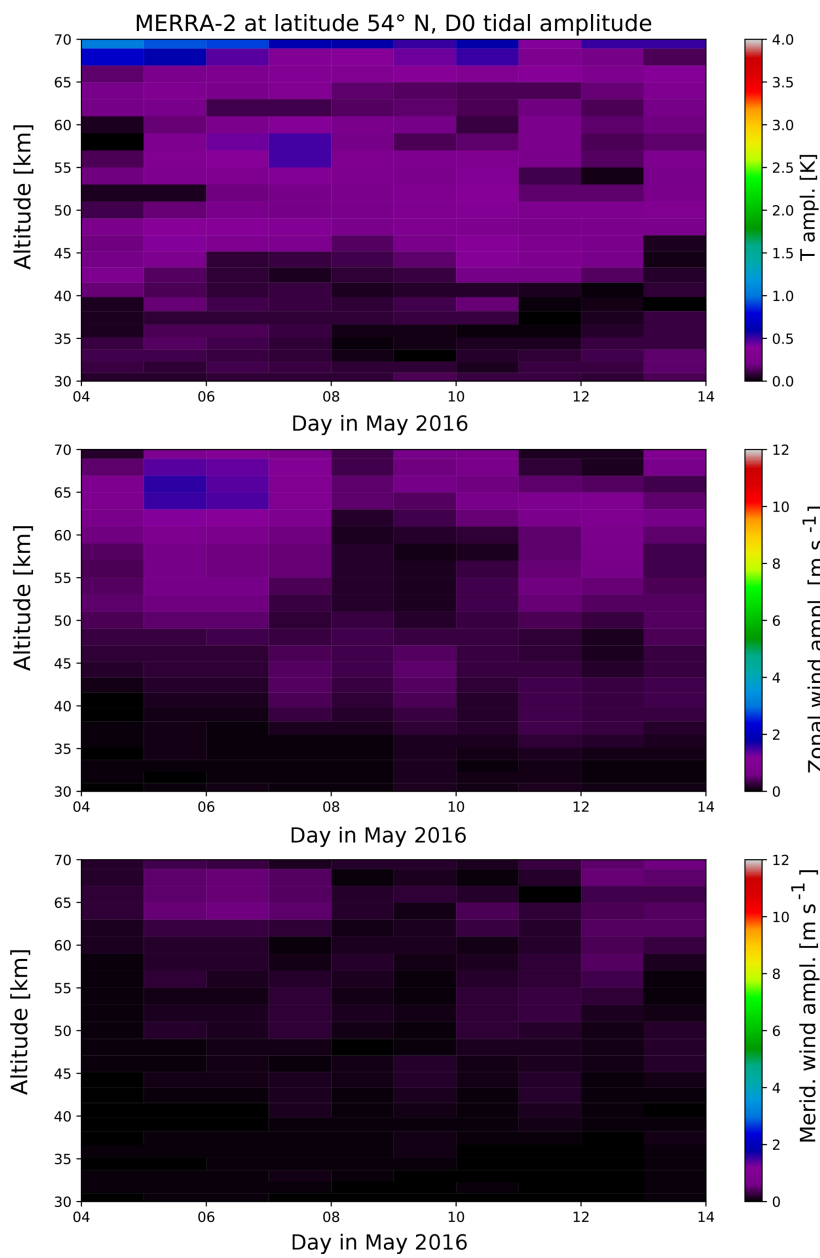

Figure A1. D0 amplitude in temperature, zonal and meridional wind from global MERRA-2 fields at the latitude of $54^{\circ} \mathrm{N}$.
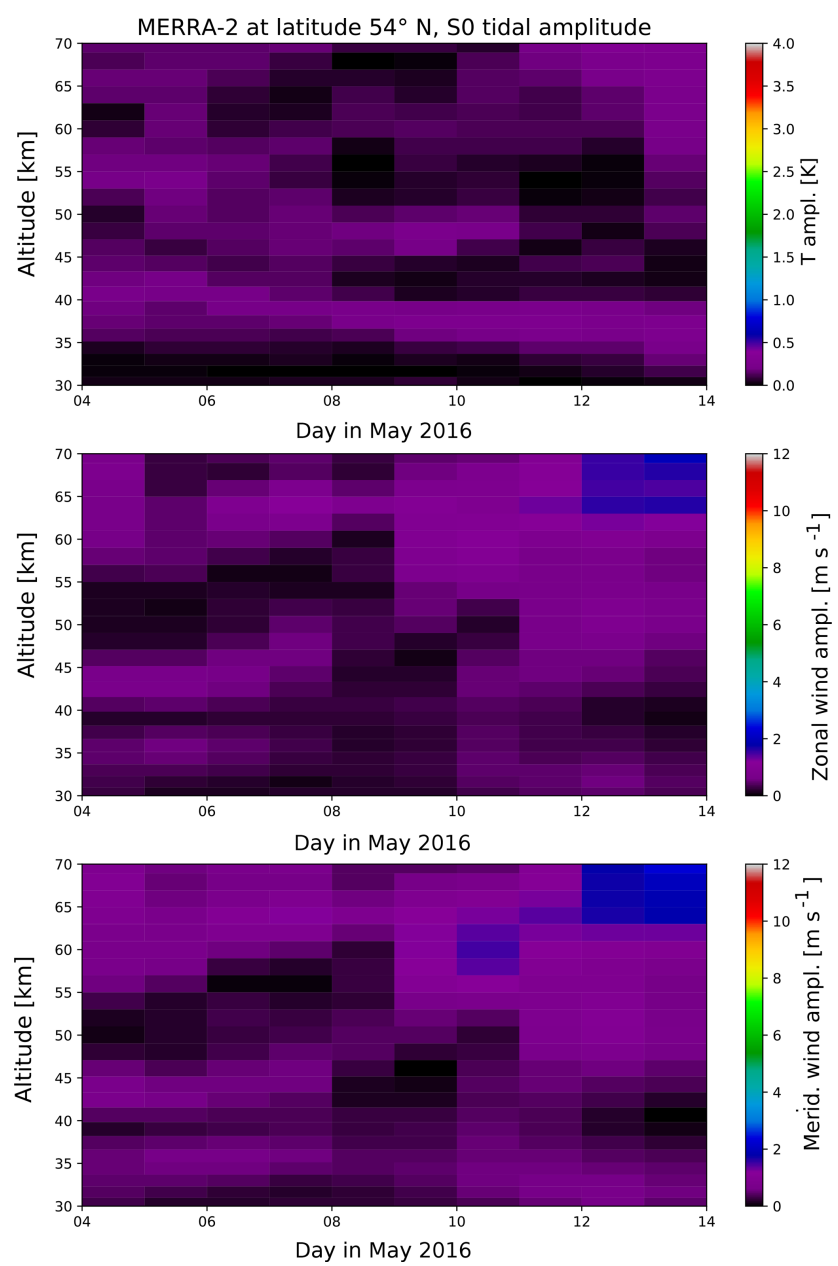

Figure A2. S0 amplitude in temperature, zonal and meridional wind from global MERRA-2 fields at the latitude of $54^{\circ} \mathrm{N}$. 

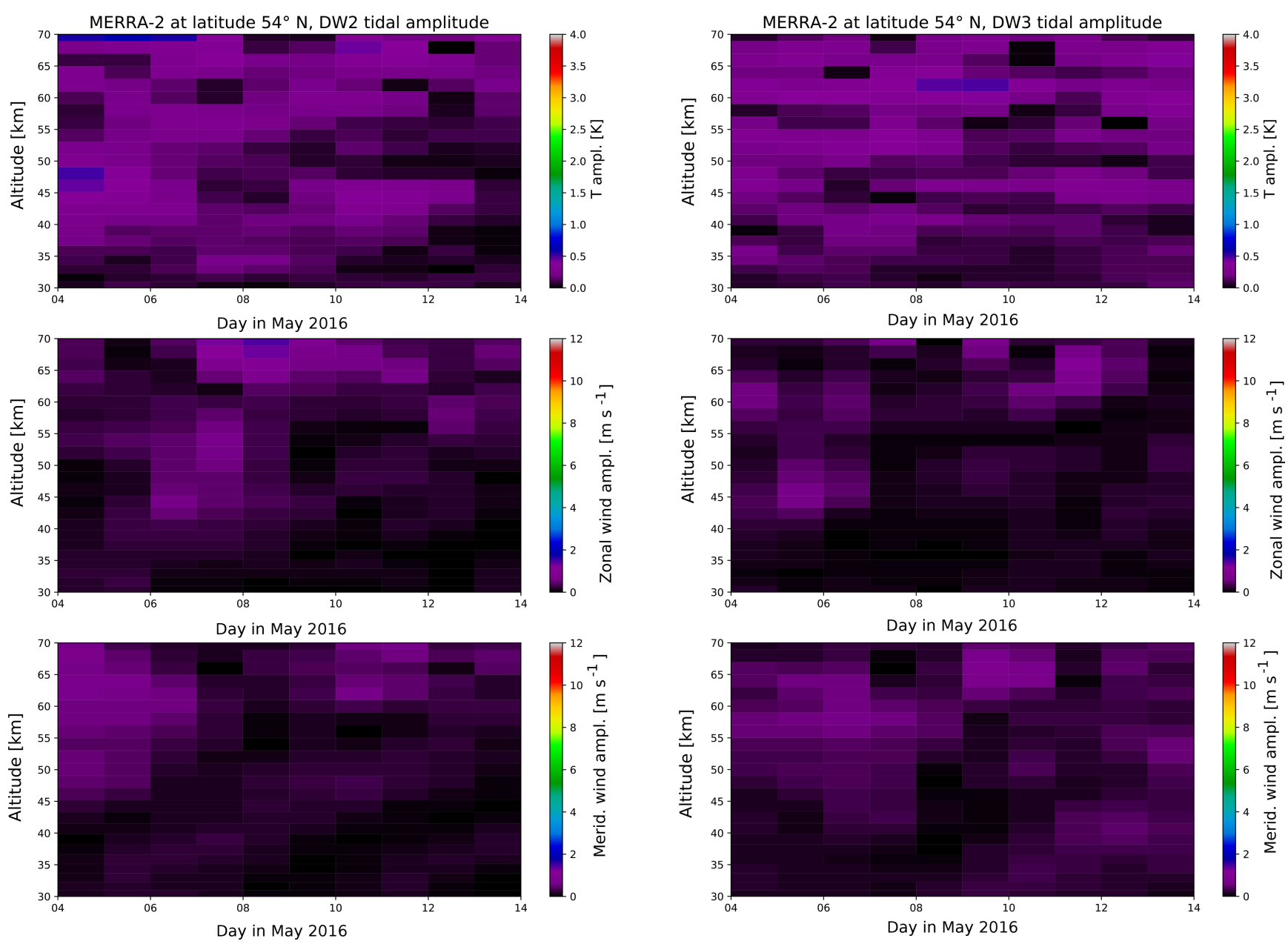

Figure A3. DW2 amplitude in temperature, zonal and meridional wind from global MERRA-2 fields at the latitude of $54^{\circ} \mathrm{N}$.

Figure A4. DW3 amplitude in temperature, zonal and meridional wind from global MERRA-2 fields at the latitude of $54^{\circ} \mathrm{N}$. 

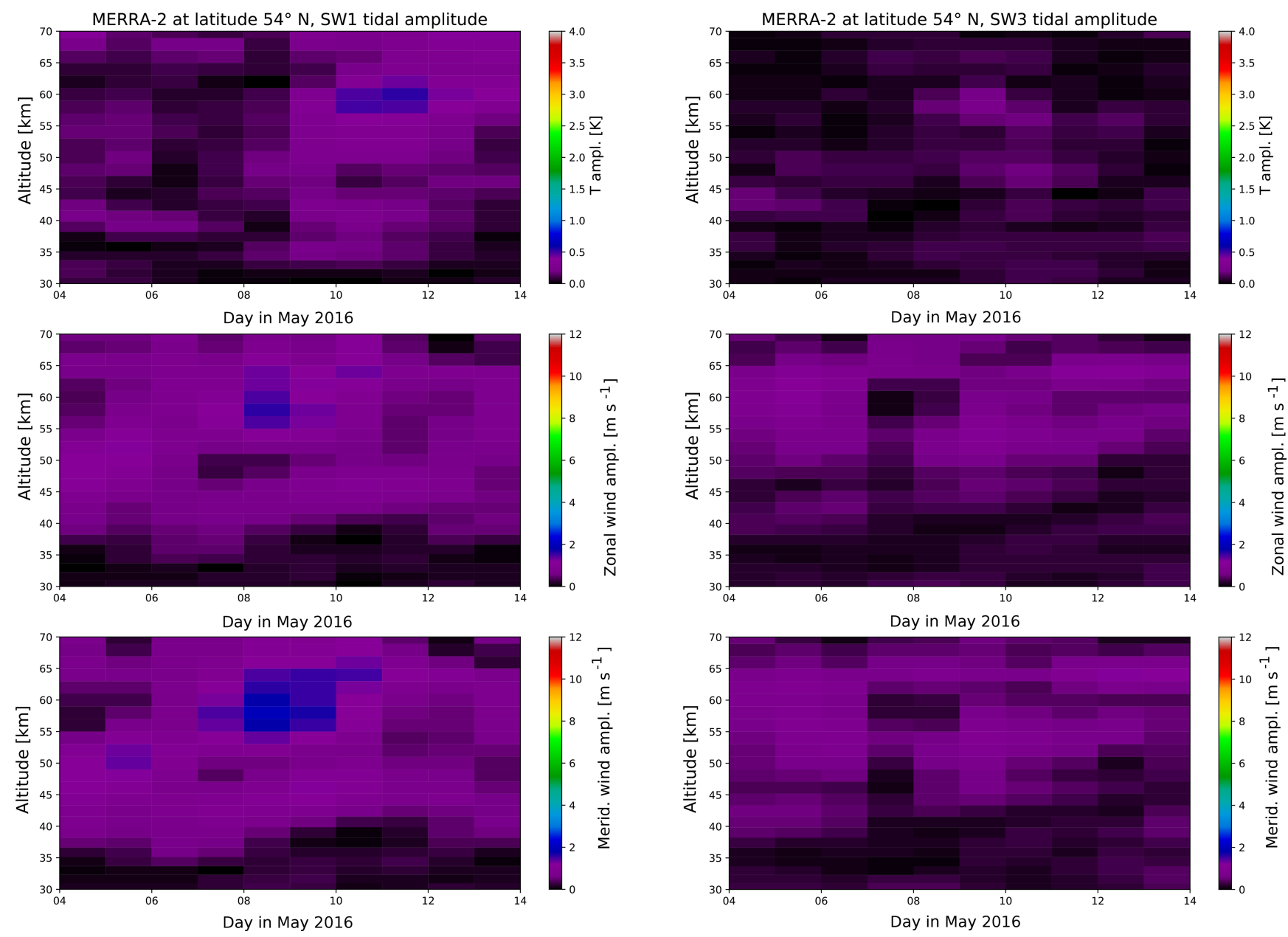

Figure A5. SW1 amplitude in temperature, zonal and meridional wind from global MERRA-2 fields at the latitude of $54^{\circ} \mathrm{N}$.

Figure A6. SW3 amplitude in temperature, zonal and meridional wind from global MERRA-2 fields at the latitude of $54^{\circ} \mathrm{N}$. 

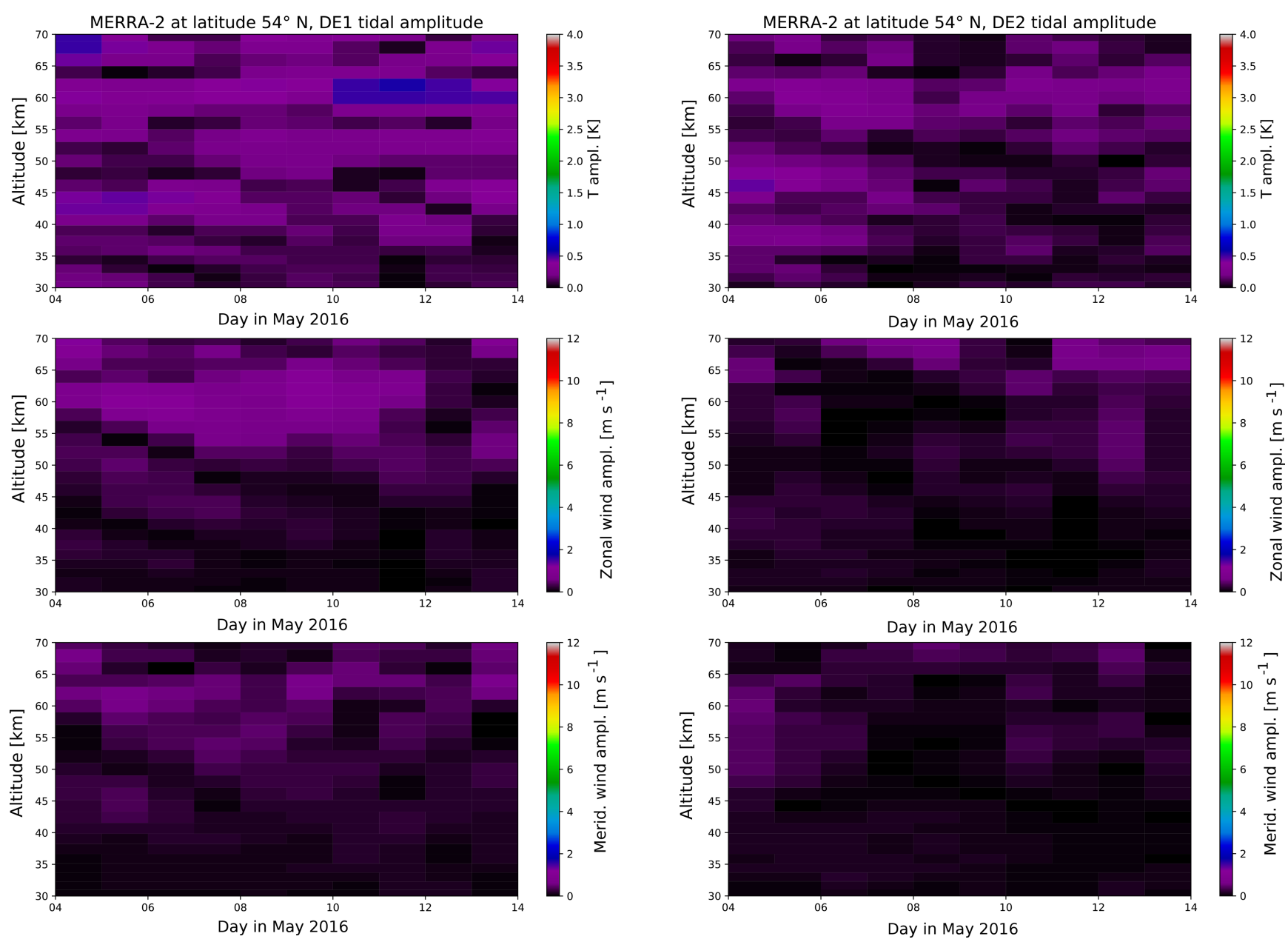

Figure A7. DE1 amplitude in temperature, zonal and meridional wind from global MERRA-2 fields at the latitude of $54^{\circ} \mathrm{N}$.

Figure A8. DE2 amplitude in temperature, zonal and meridional wind from global MERRA-2 fields at the latitude of $54^{\circ} \mathrm{N}$. 

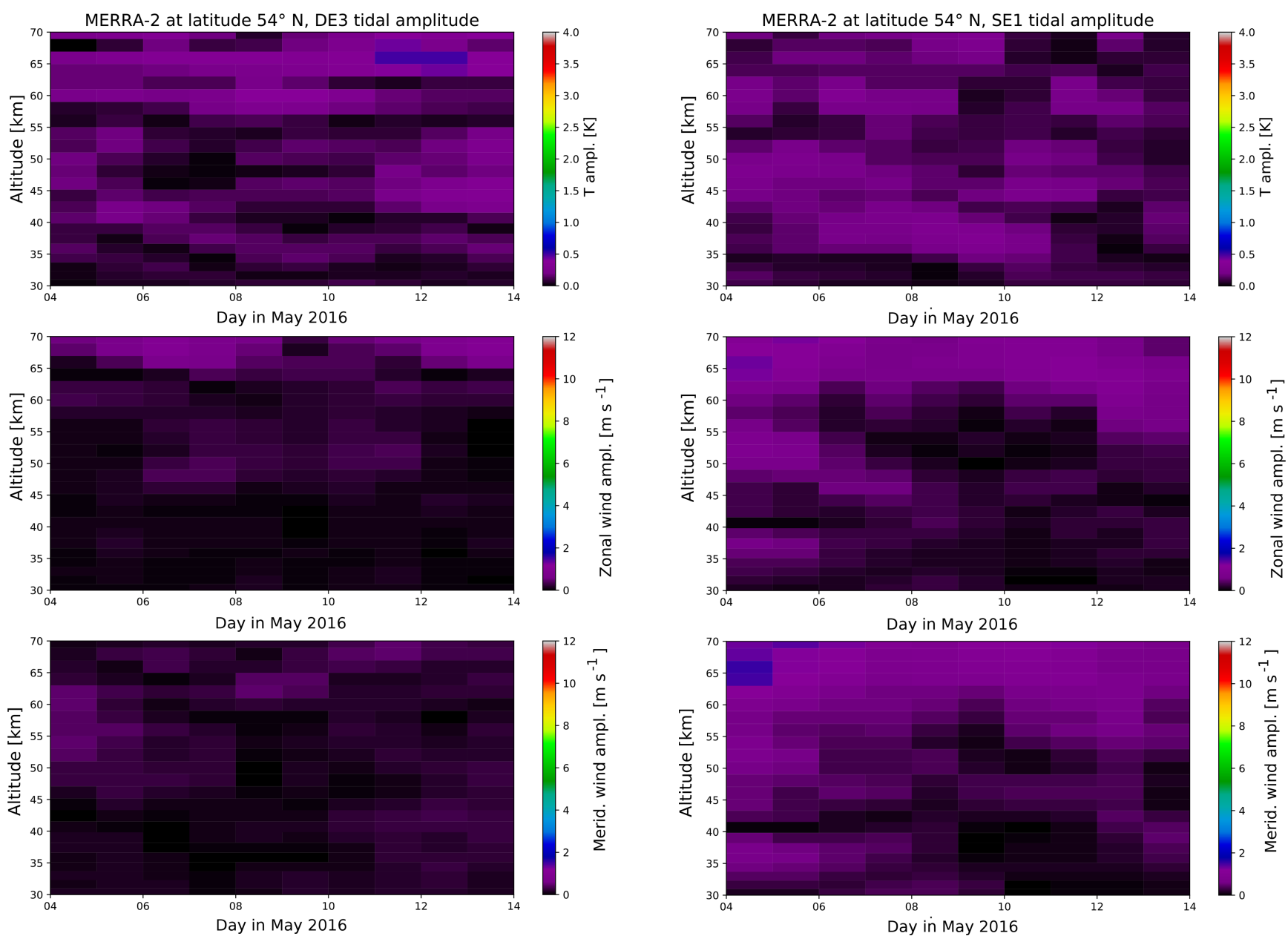

Figure A9. DE3 amplitude in temperature, zonal and meridional wind from global MERRA-2 fields at the latitude of $54^{\circ} \mathrm{N}$.

Figure A10. SE1 amplitude in temperature, zonal and meridional wind from global MERRA-2 fields at the latitude of $54^{\circ} \mathrm{N}$. 

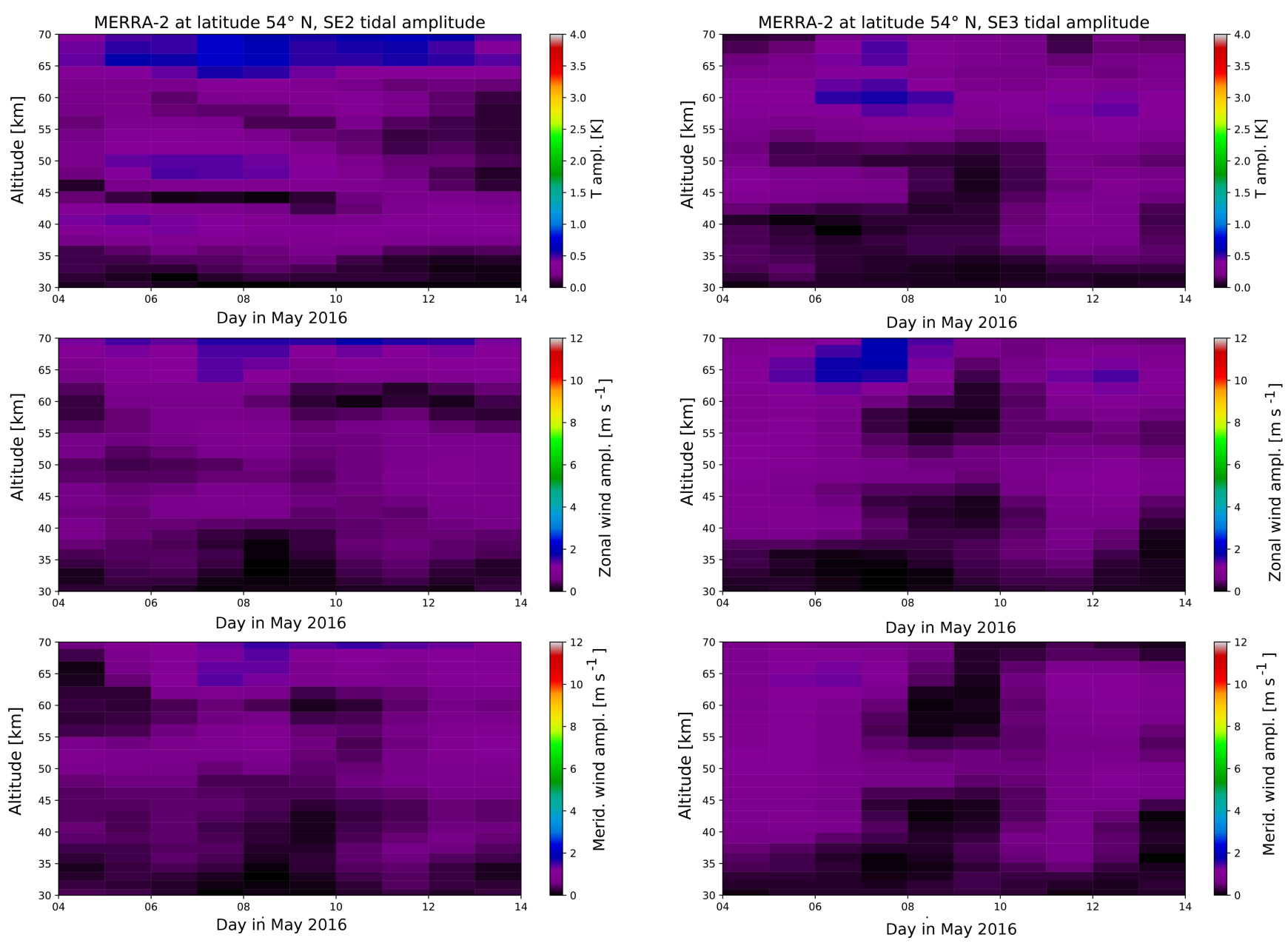

Figure A11. SE2 amplitude in temperature, zonal and meridional wind from global MERRA-2 fields at the latitude of $54^{\circ} \mathrm{N}$.

Figure A12. SE3 amplitude in temperature, zonal and meridional wind from global MERRA-2 fields at the latitude of $54^{\circ} \mathrm{N}$. 
Author contributions. KB calculated the lidar temperature data, visualized and interpreted the temperature and wind data from the lidar and MERRA-2, and drafted the first version of the paper. GS wrote the data analysis code, provided the MERRA-2 data, performed the analysis and discussed the findings.

Competing interests. The authors declare that they have no conflict of interest.

Special issue statement. This article is part of the special issue "Vertical coupling in the atmosphere-ionosphere system". It is a result of the 7th Vertical coupling workshop, Potsdam, Germany, 2-6 July 2018.

Acknowledgements. We gratefully acknowledge Michael Gerding for his helpful comments and for being the responsible scientist of the RMR lidar system at the Leibniz-Institute of Atmospheric Physics (IAP). We also thank Maren Kopp and Josef Höffner for their help in the installation of the daylight-capable RMR lidar as well as Michael Priester and Torsten Köpnick for the maintenance and operation of the RMR lidar system. We also acknowledge all students for helping in lidar operation. We thank the tidal matrix group at IAP for fruitful discussions.

Financial support. This work was partially supported by the Deutsche Forschungsgemeinschaft (DFG; German Research Foundation) under the SPP1788 (DynamicEarth) project DYNAMITE (CH1482/1-1) as well as under project LU1174/8-1 (PACOG) of the research unit FOR1898.

The publication of this article was funded by the Open Access Fund of the Leibniz Association.

Review statement. This paper was edited by Petra Koucka Knizova and reviewed by two anonymous referees.

\section{References}

Baumgarten, K., Gerding, M., and Lübken, F.-J.: Seasonal variation of gravity wave parameters using different filter methods with daylight lidar measurements at midlatitudes, J. Geophys. Res.-Atmos., 122, 2683-2695, https://doi.org/10.1002/2016JD025916, 2017.

Baumgarten, K., Gerding, M., Baumgarten, G., and Lübken, F.-J.: Temporal variability of tidal and gravity waves during a record long 10-day continuous lidar sounding, Atmos. Chem. Phys., 18, 371-384, https://doi.org/10.5194/acp-18-371-2018, 2018.

Becker, E.: Mean-Flow Effects of Thermal Tides in the Mesosphere and Lower Thermosphere, J. Atmos. Sci., 74, 2043-2063, https://doi.org/10.1175/JAS-D-16-0194.1, 2017.

Chapman, S. and Lindzen, R. S.: Atmospheric tides: Thermal and Gravitational, Gordon and Breach, New York, 1970.
Ehard, B., Kaifler, B., Kaifler, N., and Rapp, M.: Evaluation of methods for gravity wave extraction from middle-atmospheric lidar temperature measurements, Atmos. Meas. Tech., 8, 46454655, https://doi.org/10.5194/amt-8-4645-2015, 2015.

Fleming, E. L., Chandra, S., Barnett, J. J., and Corney, M.: Zonal mean temperature, pressure, zonal wind, and geopotential height as functions of latitude, Adv. Space Res., 10, 11-59, 1990.

Fong, W., Lu, X., Chu, X., Fuller-Rowell, T. J., Yu, Z., Roberts, B. R., Chen, C., Gardner, C. S., and McDonald, A. J.: Winter temperature tides from 30 to $110 \mathrm{~km}$ at McMurdo $\left(77.8^{\circ} \mathrm{S}, 166.7^{\circ} \mathrm{E}\right)$, Antarctica: Lidar observations and comparisons with WAM, J. Geophys. Res.-Atmos., 119, 2846-2863, https://doi.org/10.1002/2013JD020784, 2014.

Forbes, J. M.: Middle atmosphere tides, J. Atmos. Terr. Phys., 46, 1049-1067, 1984.

Forbes, J. M.: Tidal and Planetary Waves, 67-87, Geophysical Monograph Series, American Geophysical Union, https://doi.org/10.1029/GM087p0067, 1995.

Forbes, J. M. and Garrett, H. B.: Theoretical studies of atmospheric tides, Rev. Geophys., 17, 1951-1981, https://doi.org/10.1029/RG017i008p01951, 1979.

Forbes, J. M. and Hagan, M. E.: Diurnal propagating tide in the presence of mean winds and dissipation: a numerical investigation, Planet. Space Sci., 36, 579-590, https://doi.org/10.1016/0032-0633(88)90027-X, 1988.

Forbes, J. M. and Wu, D.: Solar Tides as Revealed by Measurements of Mesosphere Temperature by the MLS Experiment on UARS, J. Atmos. Sci., 63, 1776-1797, https://doi.org/10.1175/JAS3724.1, 2006.

Fritts, D. C. and Alexander, M. J.: Gravity wave dynamics and effects in the middle atmosphere, Rev. Geophys., 41, 1003, https://doi.org/10.1029/2001RG000106, 2003.

Gelaro, R., McCarty, W., Suárez, M. J., Todling, R., Molod, A., Takacs, L., Randles, C. A., Darmenov, A., Bosilovich, M. G., Reichle, R., Wargan, K., Coy, L., Cullather, R., Draper, C., Akella, S., Buchard, V., Conaty, A., da Silva, A. M., Gu, W., Kim, G.K., Koster, R., Lucchesi, R., Merkova, D., Nielsen, J. E., Partyka, G., Pawson, S., Putman, W., Rienecker, M., Schubert, S. D., Sienkiewicz, M., and Zhao, B.: The Modern-Era Retrospective Analysis for Research and Applications, Version 2 (MERRA-2), J. Climate, 30, 5419-5454, https://doi.org/10.1175/JCLI-D-160758.1, 2017.

Gerding, M., Kopp, M., Höffner, J., Baumgarten, K., and Lübken, F.-J.: Mesospheric temperature soundings with the new, daylightcapable IAP RMR lidar, Atmos. Meas. Tech., 9, 3707-3715, https://doi.org/10.5194/amt-9-3707-2016, 2016.

Hagan, M. E. and Forbes, J. M.: Migrating and nonmigrating diurnal tides in the middle and upper atmosphere excited by tropospheric latent heat release, J. Geophys. Res.-Atmos., 107, ACL 6-1-ACL 6-15, https://doi.org/10.1029/2001JD001236, 2002.

Hauchecorne, A. and Chanin, M. L.: Density and Temperature Profiles obtained by Lidar between 35 and $70 \mathrm{~km}$, Geophys. Res. Lett., 7, 565-568, 1980.

Hoffmann, P., Becker, E., Singer, W., and Placke, M.: Seasonal variation of mesospheric waves at northern middle and high latitudes, J. Atmos. Sol.-Terr. Phy., 72, 1068-1079, https://doi.org/10.1016/j.jastp.2010.07.002, 2010. 
Holton, J. R.: An introduction to dynamic meteorology, International Geophysics Series, Elsevier Academic Press, Burlington, MA, 4th Edn., 2004.

Hu, X., Liu, A. Z., Gardner, C. S., and Swenson, G. R.: Characteristics of quasi-monochromatic gravity waves observed with $\mathrm{Na}$ lidar in the mesopause region at Starfire Optical Range, NM, Geophys. Res. Lett., 29, 22-1-22-4, https://doi.org/10.1029/2002GL014975, 2002.

Jacobi, C.: 6 year mean prevailing winds and tides measured by VHF meteor radar over Collm $\left(51.3^{\circ} \mathrm{N}\right.$, 13.0 $0^{\circ}$ ), J. Atmos. Sol.-Terr. Phy., 78-79, 8-18, https://doi.org/10.1016/j.jastp.2011.04.010, 2012.

Kopp, M., Gerding, M., Höffner, J., and Lübken, F.-J.: Tidal signatures in temperatures derived from daylight lidar soundings above Kühlungsborn $\left(54^{\circ} \mathrm{N}, 12^{\circ} \mathrm{E}\right)$, J. Atmos. Sol.-Terr. Phy., 127, 37-50, https://doi.org/10.1016/j.jastp.2014.09.002, 2015.

Lieberman, R. S., Riggin, D. M., Ortland, D. A., Oberheide, J., and Siskind, D. E.: Global observations and modeling of nonmigrating diurnal tides generated by tide-planetary wave interactions, J. Geophys. Res.-Atmos., 120, 11419-11437, https://doi.org/10.1002/2015JD023739, 2015.

Lindzen, R. S.: Thermally driven diurnal tide in the atmosphere, Q. J. Roy. Meteor. Soc., 93, 18-42, https://doi.org/10.1002/qj.49709339503, 1967.

McLandress, C., Shepherd, G. G., and Solheim, B. H.: Satellite observations of thermospheric tides: Results from the Wind Imaging Interferometer on UARS, J. Geophys. Res.-Atmos., 101, 4093-4114, https://doi.org/10.1029/95JD03359, 1996.

Mukhtarov, P., Pancheva, D., and Andonov, B.: Global structure and seasonal and interannual variability of the migrating diurnal tide seen in the SABER/TIMED temperatures between 20 and $120 \mathrm{~km}$, J. Geophys. Res.-Space, 114, A02309, https://doi.org/10.1029/2008JA013759, 2009.

Oberheide, J., Hagan, M. E., Roble, R. G., and Offermann, D.: Sources of nonmigrating tides in the tropical middle atmosphere, J. Geophys. Res.-Atmos., 107, ACL 6-1-ACL 6-14, https://doi.org/10.1029/2002JD002220, 2002.

Oberheide, J., Hagan, M., Richmond, A., and Forbes, J.: DYNAMICAL METEOROLOGY, Atmospheric Tides, in: Encyclopedia of Atmospheric Sciences, edited by: North, G. R., Pyle, J., and Zhang, F., 287-297, Academic Press, Oxford, 2nd Edn., https://doi.org/10.1016/B978-0-12-382225-3.00409-6, 2015.

Pancheva, D., Mukhtarov, P., and Smith, A. K.: Climatology of the migrating terdiurnal tide (TW3) in SABER/TIMED temperatures, J. Geophys. Res.-Space, 118, 1755-1767, https://doi.org/10.1002/jgra.50207, 2013.

Pedatella, N. M., Oberheide, J., Sutton, E. K., Liu, H.L., Anderson, J. L., and Raeder, K.: Short-term nonmigrating tide variability in the mesosphere, thermosphere, and ionosphere, J. Geophys. Res.-Space, 121, 3621-3633, https://doi.org/10.1002/2016JA022528, 2016.
Pokhotelov, D., Becker, E., Stober, G., and Chau, J. L.: Seasonal variability of atmospheric tides in the mesosphere and lower thermosphere: meteor radar data and simulations, Ann. Geophys., 36, 825-830, https://doi.org/10.5194/angeo-36-825-2018, 2018.

Sakazaki, T., Fujiwara, M., Zhang, X., Hagan, M. E., and Forbes, J. M.: Diurnal tides from the troposphere to the lower mesosphere as deduced from TIMED/SABER satellite data and six global reanalysis data sets, J. Geophys. Res.-Atmos., 117, d13108, https://doi.org/10.1029/2011JD017117, 2012.

Sakazaki, T., Sato, K., Kawatani, Y., and Watanabe, S.: Three-dimensional structures of tropical nonmigrating tides in a high-vertical-resolution general circulation model, J. Geophys. Res.-Atmos., 120, 1759-1775, https://doi.org/10.1002/2014JD022464, 2015.

Sakazaki, T., Fujiwara, M., and Shiotani, M.: Representation of solar tides in the stratosphere and lower mesosphere in state-of-the-art reanalyses and in satellite observations, Atmos. Chem. Phys., 18, 1437-1456, https://doi.org/10.5194/acp-181437-2018, 2018.

She, C.-Y., Krueger, D. A., Yuan, T., and Oberheide, J.: On the polarization relations of diurnal and semidiurnal tide in the mesopause region, J. Atmos. Sol.-Terr. Phy., 142, 60-71, https://doi.org/10.1016/j.jastp.2016.02.024, 2016.

Smith, A. K.: Global Dynamics of the MLT, Surv. Geophys., 33, 1177-1230, https://doi.org/10.1007/s10712-012-9196-9, 2012.

Stober, G., Matthias, V., Jacobi, C., Wilhelm, S., Höffner, J., and Chau, J. L.: Exceptionally strong summer-like zonal wind reversal in the upper mesosphere during winter 2015/16, Ann. Geophys., 35, 711-720, https://doi.org/10.5194/angeo-35-711-2017, 2017.

Wilhelm, S., Stober, G., and Chau, J. L.: A comparison of 11year mesospheric and lower thermospheric winds determined by meteor and MF radar at $69^{\circ} \mathrm{N}$, Ann. Geophys., 35, 893-906, https://doi.org/10.5194/angeo-35-893-2017, 2017.

Yuan, T., She, C.-Y., Krueger, D., Reising, S. C., Zhang, X., and Forbes, J. M.: A collaborative study on temperature diurnal tide in the midlatitude mesopause region $\left(41^{\circ} \mathrm{N}, 105^{\circ} \mathrm{W}\right)$ with $\mathrm{Na}$ lidar and TIMED/SABER observations, J. Atmos. Sol.-Terr. Phy., 72, 541-549, https://doi.org/10.1016/j.jastp.2010.02.007, 2010.

Zhang, X., Forbes, J. M., Hagan, M. E., Russell, J. M., Palo, S. E., Mertens, C. J., and Mlynczak, M. G.: Monthly tidal temperatures 20-120 km from TIMED/SABER, J. Geophys. Res.-Space, 111, A10S08, https://doi.org/10.1029/2005JA011504, 2006.

Zhou, X., Wan, W., Yu, Y., Ning, B., Hu, L., and Yue, X.: New Approach to Estimate Tidal Climatology From Ground- and SpaceBased Observations, J. Geophys. Res.-Space, 123, 5087-5101, https://doi.org/10.1029/2017JA024967, 2018. 